\title{
Advancements in Non-Invasive Biological Surface Sampling and Emerging Applications
}

\author{
Atakan Arda Nalbant $(1$ and Ezel Boyacı * \\ Department of Chemistry, Middle East Technical University, 06800 Ankara, Turkey; nalbant.atakan@metu.edu.tr \\ * Correspondence: ezel@metu.edu.tr; Tel.: +90-312-210-3208
}

Received: 8 July 2019; Accepted: 11 October 2019; Published: 4 November 2019

\begin{abstract}
Biological surfaces such as skin and ocular surface provide a plethora of information about the underlying biological activity of living organisms. However, they pose unique problems arising from their innate complexity, constant exposure of the surface to the surrounding elements, and the general requirement of any sampling method to be as minimally invasive as possible. Therefore, it is challenging but also rewarding to develop novel analytical tools that are suitable for in vivo and in situ sampling from biological surfaces. In this context, wearable extraction devices including passive samplers, extractive patches, and different microextraction technologies come forward as versatile, low-invasive, fast, and reliable sampling and sample preparation tools that are applicable for in vivo and in situ sampling. This review aims to address recent developments in non-invasive in vivo and in situ sampling methods from biological surfaces that introduce new ways and improve upon existing ones. Directions for the development of future technology and potential areas of applications such as clinical, bioanalytical, and doping analyses will also be discussed. These advancements include various types of passive samplers, hydrogels, and polydimethylsiloxane (PDMS) patches/microarrays, and other wearable extraction devices used mainly in skin sampling, among other novel techniques developed for ocular surface and oral tissue/fluid sampling.
\end{abstract}

Keywords: non-invasive sampling; wearable devices; extractive patches; skin sampling; passive sampling; green sampling technologies

\section{Introduction}

Biological surfaces provide easy-to-access information about the underlying metabolism and workings of the human body. In broad terms, there are two approaches that can be followed to gather information from biological surfaces. The first approach is the development of wearable sensors, where a direct sensing mechanism is used as a wearable device. Wearable sensors have complex designs that can track a relatively small number of compounds from various biological surfaces, or monitor the specific features of the medical condition of the wearer in different ways [1-5]. While these wearable sensors are quite intricate in their design and mechanisms, they usually provide very basic information in terms of their ability to detect only a limited number of biologically relevant information. Another approach is the development of wearable extractive sampling devices examined in this review, which can be described as being on the opposite side of the coin in the sense that they are quite simple in their design but with the help of advanced detection methods, i.e., high sensitivity mass spectrometry (MS) coupled with the myriad of ionization techniques available, provide a vast amount of information.

\section{Skin Sampling}

Sampling and profiling skin metabolites has been a topic of interest over the last several years [6-9]. The majority of the biological information is gathered from sweat, which is secreted from eccrine 
and apocrine glands, and sebum which is secreted by sebaceous glands. The sebum contains many distinctive compounds that result from the breakdown of proteins and enzymes in the outer layer of the skin, known as the epidermis [10]. The underlying biological pathways that produce these compounds in sweat, sebum, and epidermis are quite varied and the compounds of interest have a wide range of polarity, size, and structure as a result. These diverging compounds are of interest to clinical research fields such as forensics and toxicology [11-13], not to mention the obvious applications in medicinal diagnosis [14-16], doping tests [17,18], and environmental/occupational exposomics [19-21].

Some of the major difficulties in sampling skin secretions are the challenges of collecting large volumes of sweat and the low concentrations $[22,23]$ of metabolites and other compounds of interest. Therefore, initial studies in the mid-20th century required patients to sweat copious amounts into plastic skin bags, a rather exhaustive method of sample collection [24]. A more commonly employed method nowadays is to use small vessels filled with organic solvents [25] to extract metabolites from a relatively small area, but this method leaves the skin irritated and many of the organic solvents are not biocompatible nor environmentally friendly. Less invasive methods such as Macroduct ${ }^{\circledR}[26]$ and cotton pads [27] for sampling from skin surfaces as well as micro dialysis [28] and subcutaneous solid phase microextraction (SPME) [29] for sampling from inner skin layers have been developed but have some limitations. For instance, some of these methods can only be applied for one type of sample collection, e.g., only for sweat collection or only for sebum sampling. Some methods require additional sample preparation steps to be performed which are time consuming and may introduce additional errors into the analysis. There are substantial efforts to address the limits of the methods listed above and to pave the way for non-invasive, biocompatible in vivo and in situ skin sampling techniques and to integrate them with state-of-art analysis instruments.

\subsection{Direct Contact Type Sampling}

In this type of sampling approach, the sampling device, or patch, is placed directly on the skin without leaving any gap between the sampler and the surface. The advantage to this approach is that it provides good extraction capability for both volatile and non-volatile analytes. The main drawback is that many unwanted compounds can adhere to the sampling device by smearing through the skin surface resulting in a considerable amount of matrix contamination. These contaminations might affect sampler performance, resulting in absolute matrix effects, including ionization suppression/enhancement in electrospray ionization (ESI), and may cause frequent instrumental maintenance.

Patch type sampling employs sorbent materials embedded on scaffold or directly placed onto the sampling area, removed after a satisfactory sampling duration, and can either be analyzed by various analytical instrumentations allowing direct analysis (i.e., direct mass spectrometry) or be subjected to a desorption step before analysis by suitable instrumentation. Materials used in patch type sampling should be elastic enough to conform to the shape of the sampling area but resilient enough to sustain the expected wear and tear of normal daily activity if the patch is required to be left on the skin of the subject for an extended period of time. The biocompatibility of the material is another important criterion to prevent irritation of the skin for the same reasons as above.

\subsubsection{Polydimethylsiloxane (PDMS)}

PDMS has been commonly used as an extractive phase for thin film microextraction (TFME) [30,31] as well as solid phase microextraction (SPME) $[32,33]$ for various different analytes, matrices, and applications. Controlled polymerization of PDMS allows for adjustable elasticity and molding with relatively inert and biocompatible features which are useful for extended sampling periods. Thermal and chemical stability of PDMS, particularly against commonly used cleaning and surface activation solvents, further reinforces its applicability as an extractive phase for patch type sampling purposes.

PDMS can be used as an extractive phase in two different modes: first is the headspace sampling method where the material is not in direct contact with the sampling area and volatile compounds that 
emanate from skin are captured. The second mode is the direct contact mode, where the PDMS patch is directly placed on top of the sampling area. In this mode, both volatile and semi-volatile compounds can be extracted. However, the skin is usually contaminated by dust particles and many other chemicals, such as cosmetic products; therefore, the patch might convey these unwanted matrix components to the instrument. These matrix components could potentially contaminate the analytical instrument, which would require clean-up before and after each use. In an effort to prevent such compounds from adhering to the PDMS surface, Jiang et al. developed a sampling method which allowed the patch to be used either as a headspace sampling device or for direct contact type sampling from skin [34]. Jiang and colleagues employed two layers of stainless-steel mesh to separate the PDMS film from coming into direct contact with the skin, as shown in Figure 1a. In order to evaluate the reproducibility of the so-called "membrane sandwich" method, an in-vial experiment was conducted in parallel, and intra-membrane irreproducibility was found to be $9.8 \%(n=6)$ and inter-membrane reproducibility was determined to be $8.2 \%$. Inter-membrane reproducibility is particularly important for potential clinical applications, where membranes would be used only once. When detected quantities of volatile organic compounds (VOCs) were investigated, such as octanal, nonanal, and decanal, similar intensities were observed for both headspace and direct contact methods. However, for semi- and low-volatile compounds, such as 1-tetradecanol and 1-octadecanaol, higher peak intensities were observed for direct contact sampling. Some of the heavier compounds such as squalene were not detected at all by headspace sampling. These results indicate that, although the chromatograms for the headspace sampling were less contaminated by matrix related background peaks, direct sampling from the surface could be considered as a compromise between detection sensitivity and instrumental contamination. The same study also reported monitoring of food metabolites and alcohol intake directly from skin could be a potential application for such patches.

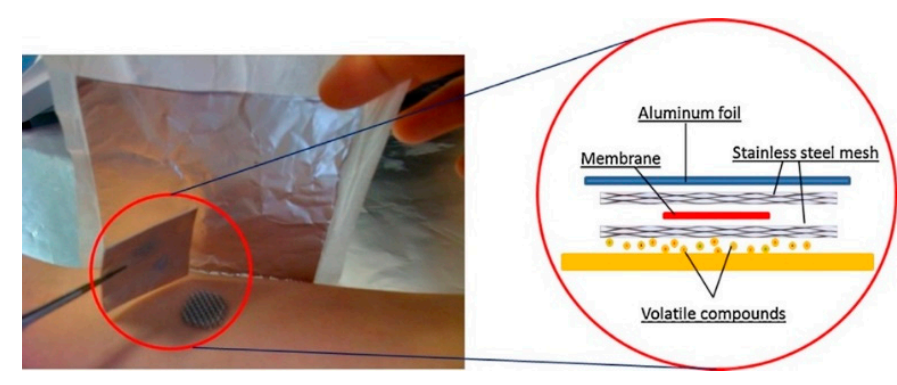

(a)

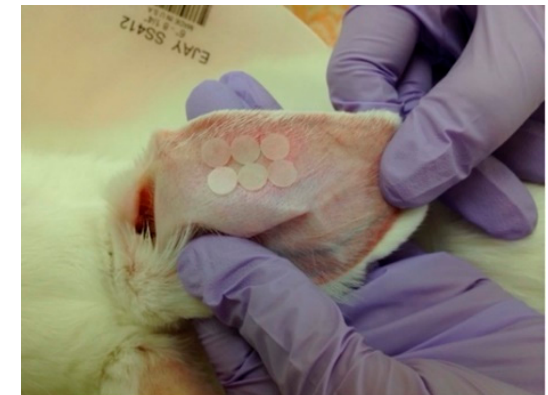

(b)

Figure 1. (a) Schematic diagram of the "membrane sandwich" headspace sampling for skin volatiles sampling. (b) Polydimethylsiloxane (PDMS) patches placed over the ventral ear surface for direct sampling. These were then covered with PTFE (polytetrafluoroethylene) and Tegaderm ${ }^{\circledR}$ (not shown). Reproduced from [34,35], with permission from Elsevier and IOP Publishing, 2019.

Direct sampling mode for PDMS were employed in many other studies showing the potential of PDMS patches for clinical applications, all highlighting the simplicity of using the patches in direct sampling mode. For instance, a rabbit model study was conducted by Schivo et al. that employed PDMS patches (Figure 1b) placed inside the ears of subjects to investigate histological evidence of early-stage ulcer formation by metabolomic screening [35]. The study results identified that the patches made of PDMS can be used for monitoring the differences between healthy and diseased skin metabolites. Approximately 150 unique skin related compounds were characterized, and 12 biologically relevant compounds were detected abundantly in the ulcer group. Most of the skin metabolites observed in the study were waxy compounds, although a large number of VOCs were detected as well. Results of the study underline that the abundance of non-volatile compounds makes direct contact sampling with PDMS a good fit and emphasize that the distribution of volatile and non-volatile compounds can be compared to human skin profile. In another study, Martin et al. 
employed PDMS patches placed onto the axilla area of female participants for VOC sampling. The study aimed to investigate skin metabolites responsible for body odor with an emphasis on the effect of a single nucleotide polymorphism 538G $\rightarrow$ A in the ABCC11 gene on the concentrations of apocrine derived axillary odor molecules, especially 3-methy-2-hexenoic acid [36]. The investigation was concluded with four volatile fatty acid (VFA) target compounds being identified with limits of detection approximately around $100 \mathrm{~s} \mathrm{pg} \mathrm{cm}{ }^{-2}$, with authors noting that a typical skin patch has an area of $0.5 \mathrm{~cm}^{2}$. It was also noted that the ABCC11 gene, other than controlling body odor, is studied for its role in breast cancer and drug resistance in cancer cells [37]. Based on the study results, combining the sampling patches with a thermal desorption unit coupled to a secondary electrospray ionization and mass spectrometry (TD-SESI-MS) setup is a promising approach for unattended automation of analysis and could be employed in non-invasive fast screening of metabolites for personalized medicine. In a pilot study [38], Martin et al. investigated changes in VOC profiles for stress-related biomarkers using PDMS devices placed on the foreheads of volunteer subjects for sample collection. The effect of stress on VOCs exhaled in breath was investigated previously [39], identifying six potential marker compounds. Similarly, the results obtained by Martin et al. suggested that some of the compounds identified in breath exhale in the previous study [39] also show altered levels in skin, namely terpenes (3-carene is suggested as a likely candidate), benzoic acid, and N-decanoic acid seem to be involved in the metabolic response to stress, which the authors believe a potential increase in oxidative metabolic pathways could be the cause of.

Moreover, a clinical study by Stevens et al. have explored the spatial distribution of bacterial populations and related VOCs using various sampling techniques, with PDMS patch type sampling being one of them [40]. In this study, PDMS patches were used for VOC sampling. Different areas of the foot, including toe clefts, and several dorsal and plantar surfaces, were sampled for microbiological and VOC analyses. Then, a spatial map of the foot was constructed for microbiological and VOC concentrations which showed significant differences between different regions. Specific volatiles such as acetic, butyric, valeric, and isovaleric acids were found in considerably high concentrations in the sole region of the foot compared to the dorsal region, and, in the case of isovaleric acid, it was never found in dorsal regions while it was readily detected on the plantar surface. Their findings indicate that key volatiles responsible for malodors are abundantly found on the sole of the foot rather than in other regions sampled in the study. This study clearly indicates that sampling from different regions of the body might give different levels of particular metabolite which could be simply related to differences in body temperature, excretion rates, or skin thickness or might be indicative of biologically relevant information. Sampling conditions of such results has to be carefully designed in order to avoid any misinterpretation.

As it has been remarked above, PDMS based patches are versatile tools and easy to adopt for numerous investigations. In addition, PDMS films can be purchased or prepared in the laboratory using well defined protocols and can be easily shaped in any size. In addition, the thermal stability of PDMS enables the thermal desorption of extracted analytes from patches using large thermal desorption units connected to gas chromatography mass spectrometry (GC-MS) [35,36,38]. However, it is worth mentioning that before use PDMS patches require extensive cleaning and activation steps that might involve a considerable amount of preparation before sampling $(4-24 \mathrm{~h})$. Therefore, it is crucial to prevent contamination at each step of the workflow including cleaning/pre-treatment and sampling. Moreover, during the sampling, PDMS patches should be protected from environmental wear and tear and possible contaminations by a placing a durable cover over them, as shown by Schivo et al. in their pilot study [35].

\subsubsection{Agarose Hydrogel}

Agarose hydrogel is another commonly used material for direct contact type sampling. Agarose hydrogel lacks the robustness of PDMS patches, but it is more biocompatible than PDMS, as it is a naturally occurring homopolymer derived from red algae [41]. Agarose has completely different 
extractive properties suitable for hydrophilic skin metabolites owing to its complex polar structure and adjustable water content. These properties lead to agarose patches being mostly used for extraction of relatively polar metabolites as can be seen from the examples below.

For instance, Dutkiewicz et al. have developed agarose micropatches to detect several low-molecular-weight skin metabolites as a proof-of-concept study [42]. In this study, the lack of robustness of agarose hydrogels was overcome by embedding them inside cavities on a PTFE chip. Various prevalent skin metabolites were detected, and some were identified, as given in Table 1. The authors stated that high signal-to-noise ratios were achieved for clinically relevant analytes. In another study, Dutkiewicz et al. also employed micropatch-arrayed pads (MAPAs) to profile topically applied drugs. In this study, five rows of five cavities, a total of 25 , containing agarose hydrogels were applied to both in vivo human skin and ex vivo porcine skin by self-adhesive 3-D printed PTFE scaffolds [43]. In a later study by the same group, MAPAs were implemented to investigate psoriasis-related skin metabolites and an automated diagnostic method was developed with satisfactory results that imply clinical use of MAPAs is a reasonable possibility [44]. A number of metabolites, namely choline, citrulline, glutamic acid, urocanic acid, lactic acid, and phenylalanine, were discovered to have altered concentrations in diseased skin areas, indicating they are related to psoriasis metabolism. One of the key advantages of MAPAs is the direct coupling with nano desorption electrospray ionization (nanoDESI). In this approach, a solvent mixture can be continuously pumped through a capillary to one of the hydrogel micropatches while another capillary delivers the solvent to the nanoDESI loading dock. This approach eliminates further steps (e.g., desorption, pre-concentration, etc.) and provides a quick and simple online method for direct mass spectrometric analysis.

Table 1. Identification of peaks in the mass spectra of sweat [44].

\begin{tabular}{|c|c|c|c|c|c|c|c|}
\hline $\begin{array}{l}\text { Peak } \\
\text { No }\end{array}$ & $m / z^{*}$ (IT) & $\begin{array}{c}m / z^{*}(\mathbf{F T}- \\
\text { ICR) }\end{array}$ & $\begin{array}{l}\text { Metabolite } \\
\text { Formula }\end{array}$ & Metabolite Name & $\begin{array}{c}\text { Predicted }^{b} \\
\qquad / z^{*}\end{array}$ & MS/MS & $\begin{array}{c}\text { Compared with } \\
\text { Standard }\end{array}$ \\
\hline 1 & 89.0 & 89.02438 & $\mathrm{C}_{3} \mathrm{H}_{6} \mathrm{O}_{3}$ & lactic acid & 89.02442 & + & + \\
\hline 2 & 93.0 & 93.04578 & $\mathrm{C}_{5} \mathrm{H}_{6} \mathrm{~N}_{2}$ & fragment of uronic acid & 93.04582 & + & + \\
\hline 3 & 104.0 & 104.03530 & $\mathrm{C}_{3} \mathrm{H}_{7} \mathrm{NO}_{3}$ & serine & 104.03532 & + & + \\
\hline 4 & 118.0 & 118.05089 & $\mathrm{C}_{4} \mathrm{H}_{9} \mathrm{NO}_{3}$ & threonine & 118.05097 & + & + \\
\hline 5 & 128.0 & 128.03530 & $\mathrm{C}_{5} \mathrm{H}_{7} \mathrm{NO}_{3}$ & pyroglutamic acid & 128.03532 & + & + \\
\hline 6 & 131.0 & 131.08259 & $\mathrm{C}_{5} \mathrm{H}_{12} \mathrm{~N}_{2} \mathrm{O}_{2}$ & ornithine $^{\mathrm{a}}$ & 131.08260 & + & - \\
\hline 7 & 137.0 & 137.03561 & $\mathrm{C}_{6} \mathrm{H}_{6} \mathrm{~N}_{2} \mathrm{O}_{2}$ & urocanic acid & 137.03565 & + & + \\
\hline 8 & 154.0 & 154.06218 & $\mathrm{C}_{6} \mathrm{H}_{9} \mathrm{~N}_{3} \mathrm{O}_{2}$ & histidine $^{\mathrm{a}}$ & 154.06220 & + & - \\
\hline 9 & 179.0 & 179.05731 & $\mathrm{C}_{7} \mathrm{H}_{8} \mathrm{~N}_{4} \mathrm{O}_{2}$ & paraxanthine ${ }^{a}$ & 179.05745 & - & - \\
\hline
\end{tabular}

${ }^{a}$ Putative formula and name of the metabolite. ${ }^{b}$ Values calculated for $[\mathrm{M}-\mathrm{H}]^{-}$ions (mass of an electron is included). ${ }^{*} \mathrm{~m} / \mathrm{z}$ : mass-to-charge ratio. IT: ion trap; FT-ICR: Fourier transform ion cyclotron resonance. Reproduced from [44], with permission from ACS Publications, 2019.

As it has been pointed out several times by now in the studies shown above, agarose hydrogels are limited for extraction of relatively polar analytes. This limitation narrows the biologically relevant information that can be obtained from the studied system. Other biocompatible hydrogels, such as gelatin and polyvinyl pyrrolidone, could potentially offer the same, or even greater, advantage for skin sampling and further functionalization of agarose or other hydrogels could very well be a prospective area of research in the future. Selective sampling can be also be achieved by using copolymers of different hydrogels with different functional groups to target compounds with varying polarities.

\subsubsection{Microneedle Arrays}

In recent years there has been considerable effort to employ low-invasive microneedle structures (<1-mm long, hollow structures) in drug delivery through skin [45,46]. More recently, this technique was modified to be employed in capturing circulating biomarkers [47-52], combining microneedle structures with biomarker-based immunoassay approach. This was achieved by functionalizing the tips of the microneedles with specific antibodies. Although functionalized microarrays provide high selectivity and could benefit many clinical diagnostic applications, only a limited number of 
studies showing the potential of the approach have been conducted. In one of the studies, $\mathrm{Ng}$ et al. developed a multiplex microneedle device coupled with a blotting method for fast and selective detection of multiple selected biomarkers from skin surface [53]. Microneedle devices were produced by micromoulding: polylactic acid (PLA) was melted in vacuo into the template micromould which was produced from the Sylgard ${ }^{\circledR} 184$ (PDMS) elastomer and surface activated using chemical methods. Surface characterization of the PLA microneedle device was performed using a scanning electron microscope (SEM) at various production stages, which can be seen in Figure 2. For immobilization of different antibodies on the multiplex microneedle device, each microneedle array was individually dipped into the desired antibody solution 10 times. Microneedle arrays were then placed for $1 \mathrm{~h}$ on mice skin doped with mouse (Interleukin 6 and 1) as well as human (Tumor Necrosis Factor alpha) antigens. After successful antigen capture, two detection methods were employed: UV/Vis spectrophotometry for quantitative detection and scanning the images of blotting patterns left by the microneedles for qualitative visualization. Blotting technique employed by the authors should be further underlined as it requires no specialized equipment and allows rapid and selective visualization of specific antigens, albeit qualitatively. It should be kept in mind that employing the detection of antigens with this method has its disadvantages such as having a limited number of antibodies that can be loaded into the microneedle arrays. Therefore, scanning for a large number of different antigens would require several runs which would increase the invasiveness of the method since different areas have to be sampled.
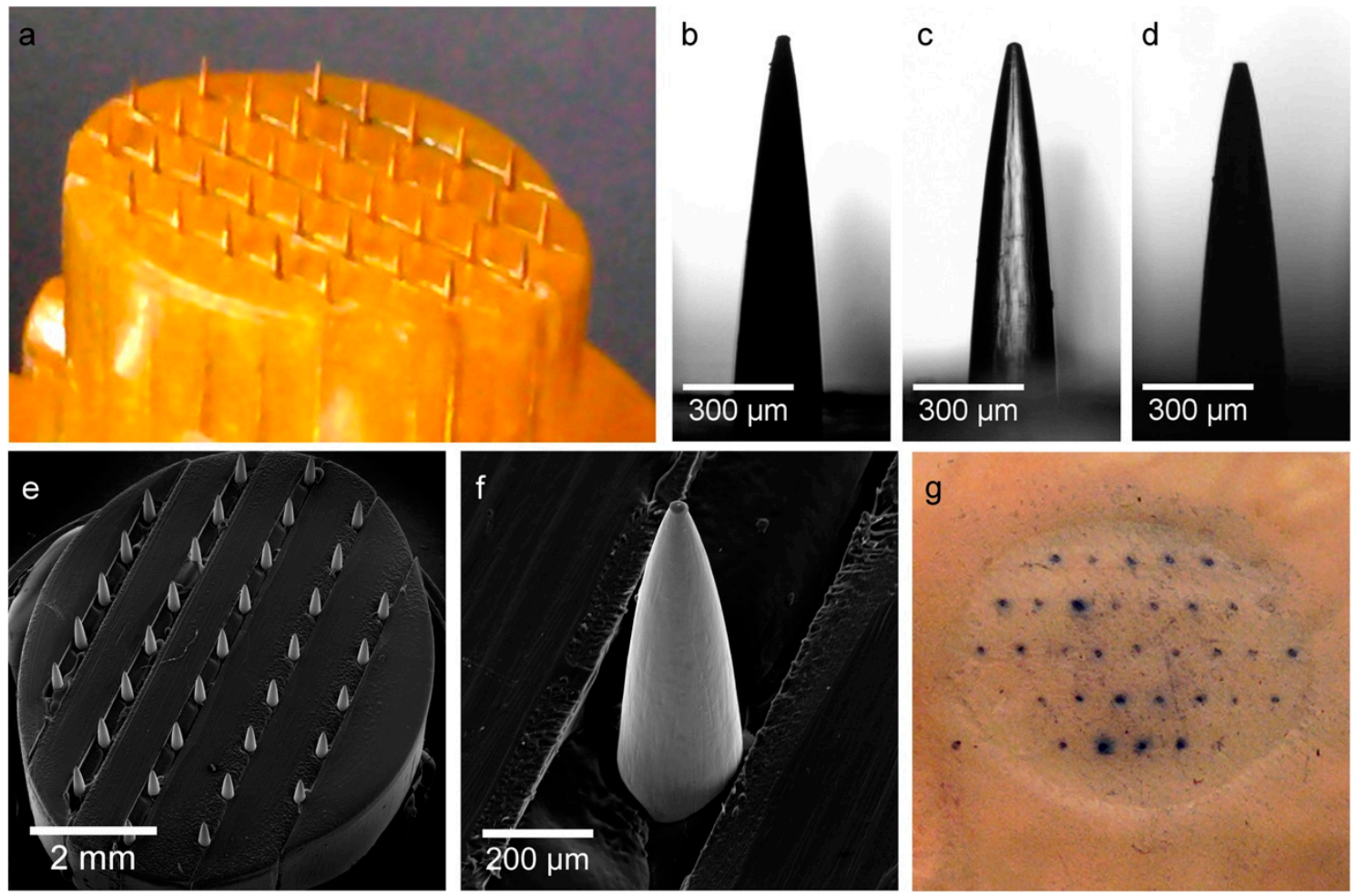

Figure 2. (a) A photograph of the template microneedle array. (b-d) Light micrographs showing: (b) a template microneedle, (c) a polylactic acid (PLA) microneedle prior to surface activation, and (d) a surface-activated PLA microneedle. (e) A surface-activated PLA microneedle array under SEM; (f) a single microneedle on this array is enlarged and shown. (g) Perforation marks on hairless mouse skin, visualized by methylene blue staining. Reproduced from [53], with permission from Springer, 2019.

Microneedle arrays, as indicated by this study, show promise as a low-invasive method that can be employed in diagnosis of skin diseases. The highly selective nature of using antibodies further promotes their diagnostic potential since extensively studied diseases can be targeted by specifically 
targeting selected antigens. Creative approaches to the geometric structures of the arrays may allow the number of microneedles in the same area to be increased, enabling more antigens to be detected.

\subsection{Headspace Sampling}

\subsubsection{Conventional SPME Fibers}

Patch type or other contact-based sampling methods [6,34-36,38,54-56] may not always be preferable for skin VOC analysis as contamination and introduction of non-volatile compounds is always a possibility. Headspace SPME is a commonly used sampling approach preferred for extracting volatiles present in various samples including complex matrices [57-60]. Several studies have scrutinized their applicability for analysis of skin VOCs [61,62] albeit not without its limitations due to their fragility, which is one of the main reasons why in situ headspace sampling is practiced in controlled environments. A simple solution for this problem is employing a housing for the SPME fibers during the sampling. This approach creates a controlled environment and ensures that extracted analytes on the fiber are only associated with the sampling area. Similar to how PDMS and agarose patches can be protected by durable covers or by being placed on PTFE scaffolds, Duffy et al. have shown that headspace SPME fibers can be protected by using wearable housing vials, seen in Figure 3a [63]. In this study, researchers compared skin VOCs before and after the acute barrier disruption of the sampling area by tape stripping to simulate impaired skin. After tape stripping, commercial divinylbenzene/carboxen/polydimethylsiloxane Stableflex fibers were used to sample skin VOCs. A total of 37 compounds were identified that were significantly altered after barrier disruption, mainly consisting of aldehydes (hexanal, nonanal, decanal), acids (nonanoic, decanoic, dodecanoic, tetradecanoic and pentadecanoic acids), and hydrocarbons (squalene). Duffy et al. have also utilized their wearable headspace SPME device in another study to investigate fragrance longevity and scent profiles of participants. In this study, skin VOCs of volunteers were analyzed before and after fragrance-derived compounds were applied to their skin to compare the difference and fragrance permanence [64]. Following the instrumental analysis, 32 fragrance-derived and 19 endogenous compounds were identified. Several endogenous VOCs were found to be suppressed by fragrance application, most apparent ones being 2-decanal, 2-undecenal, 1-dodecanol, pentadecanal, and octadecanoic acid. The most noticeable decrease in endogenous VOCs was observed immediately after fragrance application where several skin gland secretions and their oxidation products were not detected including acids, aldehydes, ketones, and hydrocarbons. Temporal and spatial profiling of fragrance-derived and endogenous compounds can prove unique insights to improve fragrance longevity and can lead to niche personalized fragrance production in the cosmetics industry.

As can be seen from the outlined studies, although such housings are not as practical as wearable patches described in previous section, they provide unique advantage for creating a well-controlled environment during sampling. Moreover, various commercial SPME fibers are readily available for purchase with different extractive properties and homemade fibers can be coated with materials that can be specialized for unique sampling purposes. Another important advantage of the SPME fibers is that they can be directly coupled with ambient ionization techniques such as nanoelectrospray ionization (nanoESI) [65], dielectric barrier discharge ionization (DBDI) [66], and open port probe (OPP) interfaces [67]. Direct coupling to MS instruments eliminates desorption and chromatographic separation steps from the analytical workflow, speeding up the overall process.

\subsubsection{Passive Flux Samplers}

Passive flux samplers (PFSs) are commonly employed in environmental studies to measure toxic or greenhouse gases emitted from animal slaughterhouses [68-70], greenhouses [71], and building materials [72], which was later adapted to sample VOCs emanating from skin [62]. So-called passive sampling devices (PSDs) consist of a small stainless-steel plate, a trapping filter that contains an extractive phase to extract relatively volatile analytes, a PTFE O-ring creating a headspace between 
the extractive phase and skin surface, and a back-up plate. Its schematics can be seen in Figure $3 \mathrm{~b}$. PFSs can be considered more practical and robust than wearable SPME fibers with integrated housing in terms of ease-of-use. PFSs, however, are more susceptible to the environment and there is always a possibility of environmental background to be considered when using this technique in sampling unless completely isolated from the environment. Due to their ease-of-use feature these devices can be adapted for sampling from various parts of the body and track metabolic changes associated with particular conditions. For example, a recent study by Kimura et al. investigated the causes of the characteristic "elderly body odor" by sampling from different areas of the skin from participants in three different age groups (young-, middle- and old-aged) using a passive sampling device [73]. MonoTrap ${ }^{\circledR}$ DCC18 containing octadecylsilane functionalized monolithic silicate and activated carbon as extractive media providing with a large surface area and high trapping capacity (O.D. $10 \mathrm{~mm} \times 1 \mathrm{~mm}$ thick, $>150 \mathrm{~m}^{2} \mathrm{~g}^{-1}$ ) was chosen for the study. Two compounds, 2-nonenal and diacetyl, were chosen as likely candidates to study as to the cause of the elderly body odor phenomena. The emission fluxes of the compounds with respect to sampling position (left forearm, left thigh, left calf, forehead, nape of the neck and abdomen), the effect of diffusion length on the dermal emission flux, and distribution of the emission fluxes, and changes by age and sex were investigated. Analysis of the collected samples illustrated that emission flux of 2-nonenal increases significantly with age while diacetyl was found to have the highest emission flux for middle aged participants. Moreover, male participants were found to have higher emission fluxes compared to female participants of similar age. Interestingly, out of all sampling areas, nape of the neck was found to be the most reliable sampling spot, since the emission fluxes of both compounds altered significantly in other sampling areas but remained relatively stable in this area. Due to the fact that eccrine and sebaceous glands are believed to be potential sources for both compounds, their abundant presence in the area is reasonable.

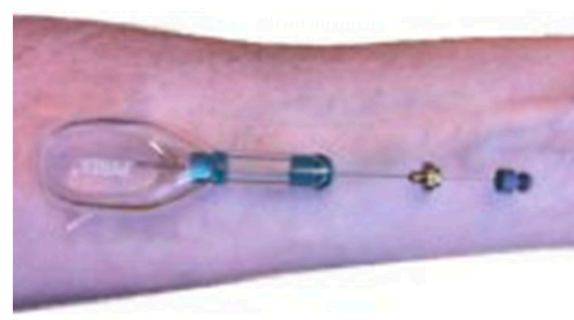

(a)

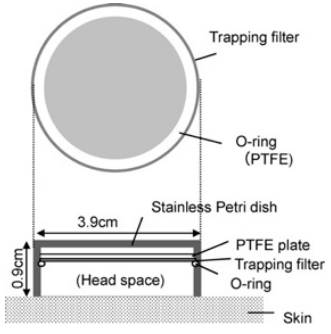

(b)

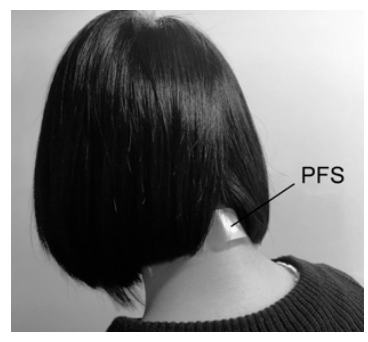

(c)

Figure 3. (a) Headspace sampling volatiles on the volar forearm using a wearable housing integrating solid phase microextraction (SPME) fiber, affixed to the skin with surgical tape. (b) Schematic view of the passive flux sampler for human skin gas. (c) Sampling of 2-nonenal and diacetyl at the nape of the neck. The PFS (passive flux sampler) was fixed by a piece of medical tape. Reproduced from [63,73], with permission from Wiley and Elsevier, 2019.

In another study, a homemade PSD (Figure 3c) was employed by Furukawa et al. to determine the whole body dermal emission rate of ammonia by taking simultaneous measurements from a total of 13 chosen spots around the body in an attempt to cover all regions of the body [74]. In order to prepare homemade PSD for ammonia, a commercial cellulose filter paper first was dipped in methanol solution containing $2 \%$ phosphoric acid and $1 \%$ glycerol and then dried under vacuum. After sampling from selected body parts, the trapped ammonia was back extracted with pure water and its concentration was determined by ion chromatography. Results revealed that the total rates of ammonia emission ranged from 2.9 to $12 \mathrm{mg} \mathrm{h}^{-1}$ with an average emission rate of $5.9 \pm 3.2 \mathrm{mg} \mathrm{h}^{-1}$ for each person. Partial emission rates obtained in the study per body part can be found below in Figure 4. Higher emission flux of ammonia was found at the feet, back, and lumbar, where large sweat glands are located, and lower flux was observed at upper arms, buttock, thighs, and legs. Based on these results the authors speculated that there are two routes for ammonia emission in the body. The first route 
follows blood ammonia, produced by metabolic reactions that involve proteins, which can directly rise to the skin surface from blood capillaries. The second proposed route is mixing of blood ammonia into sweat, which explains the increased emission flux levels in areas where sweat glands are concentrated. As can be inferred, such ease-of-use devices are very useful for tracking metabolic pathways in the human body.

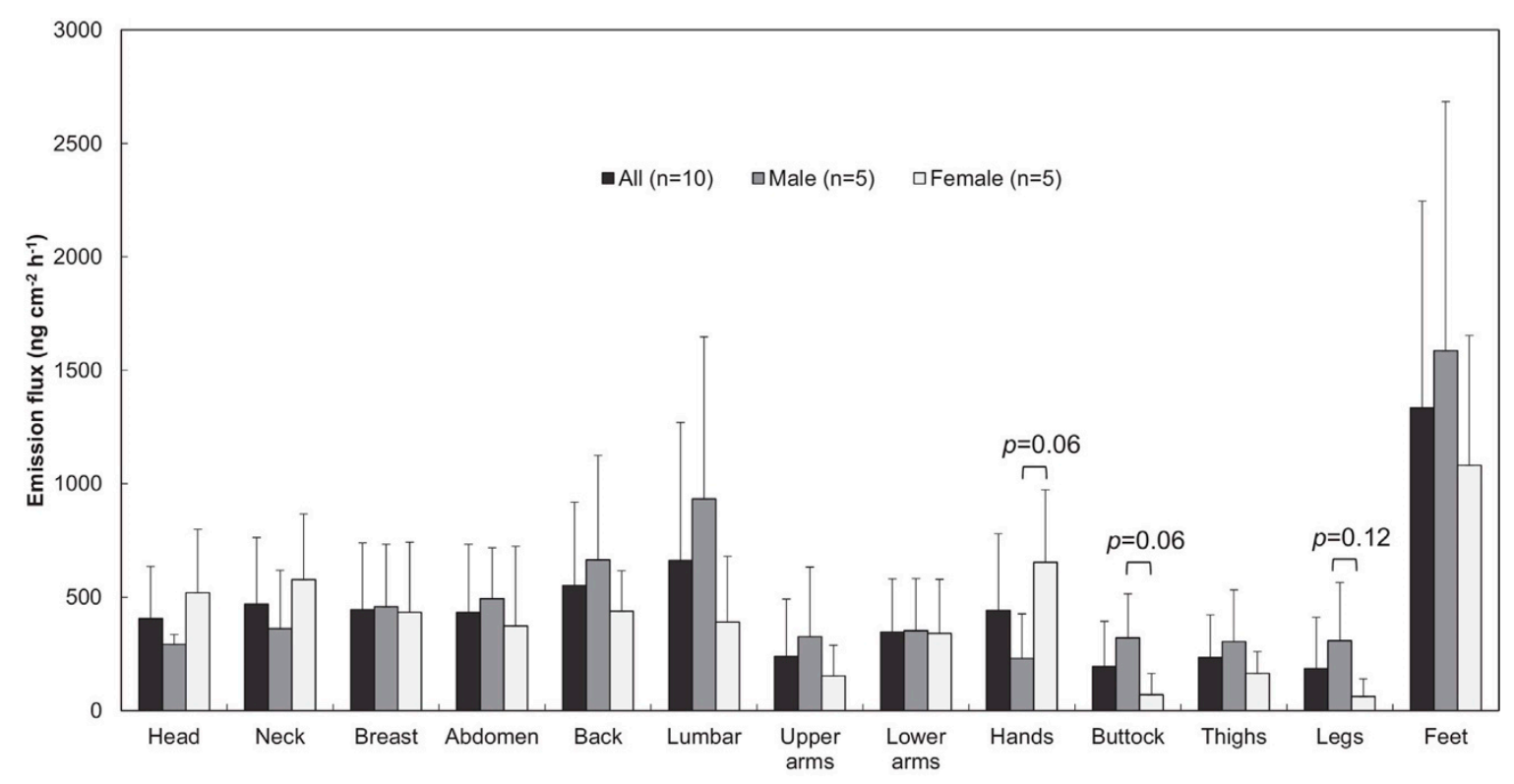

Figure 4. Comparison of emission flux of ammonia emanating from 13 sampling positions of ten volunteers. Error bars show standard deviation of measured values of tested volunteers $(n=10$ for all, $n=5$ for male, and $n=5$ for female volunteers). Reproduced from [74], with permission from Elsevier, 2019.

In addition to metabolic profiling of natural skin metabolites summarized above, there are also some preliminary studies performed using PSDs for exposomic monitoring showing the potential of wearable devices for exposure monitoring. For instance, Sekine et al. have investigated VOCs emanating from the skin of smokers and volunteers who were exposed to second hand smoke using PSDs [75]. The device employed was identical to the ones used in the group's previous studies (MonoTrap ${ }^{\circledR}$ DCC18 trapping medium). Six volunteers (four smokers and two non-smokers) participated in three different experiments to investigate the effects of cigarette smoking (for smokers) and second-hand smoke (for non-smokers) on dermal VOC emissions. PSDs were placed for $1 \mathrm{~h}$ on the forearm and the back of the hand (Figure 5a) of the volunteers. In the first test, a smoker and non-smoker volunteer stayed in the same room for $15 \mathrm{~min}$ while the smoking volunteer smoked a single cigarette. Based on the results of the first test, acetaldehyde, toluene, 3-methyl furan (3-MF), 2,5-dimethyl furan(2,5-DMF), 3-ethenyl pyridine(3-EP), and nicotine were chosen as the dermal VOCs to be investigated in further analyses. Following tests investigated the concentrations of these compounds in smokers and non-smokers (through second-hand smoking) in different conditions. Results revealed that for smokers, there is an initial spike in nicotine and its derivative 3-EP immediately after smoking which decreases to its initial value after $2 \mathrm{~h}$. In the case of secondhand smokers, the maximum dermal emission for the same compound was observed at the 2-h mark indicating that cigarette smoke has different routes of entrance to body. Another interesting result obtained in this study revealed that there is higher skin emanation of 3-MF, 2,5-DMF, 3-EP, and nicotine when a non-smoking volunteer was exposed to direct smoke emanating from a burning cigarette compared to skin emanation when the same volunteer was exposed to environmental second hand smoke. Another recent study investigating the biotic and abiotic exposome was able to successfully use a home-made wearable passive sampling device containing 3D printed cartridge filled with molecular sieves (zeolite), capable of adsorbing 
both relatively polar and non-polar compounds [76]. The cartridge was attached to the particle free air flow apparatus producing a portable device collecting both biotic and abiotic species from the exposed environment with a constant rate of sampling at $0.5 \mathrm{~L} \mathrm{~min}^{-1}$. In the study, 15 participants were monitored for a time span covering up to two years in over more than 60 different geographical locations. The sampling was performed by wearing the device when possible or keeping it in two-meter proximity to the participant when it was not possible to wear the device. The study results revealed that the human exposome is varied and dynamic and closely effected by parameters including lifestyle, environment, geographic location, as well as that it can be unique for each person even for people living under similar environmental conditions. Both studies clearly highlight the importance of wearable extractive devices for monitoring public health, microbiome, and environmental exposure to chemicals just to name a few.

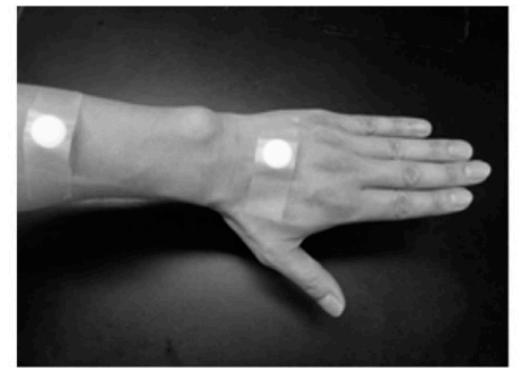

(a)

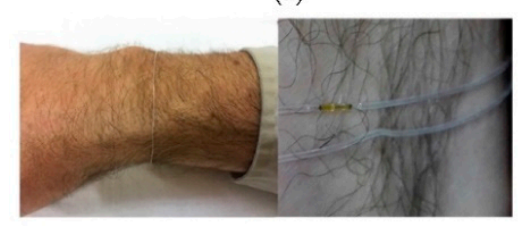

(b)

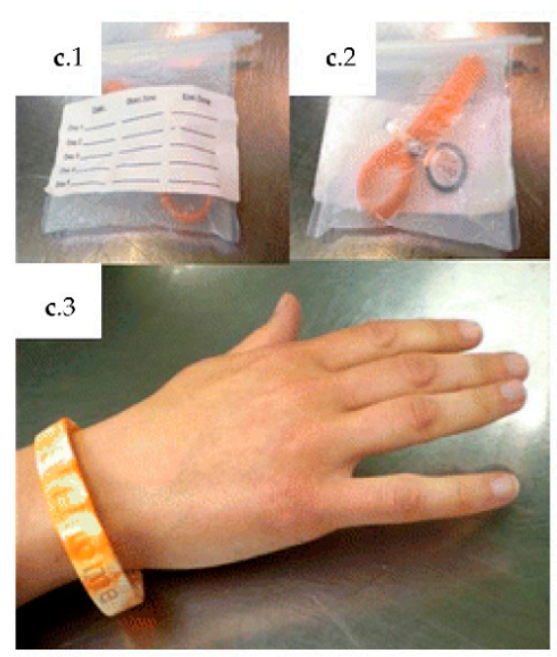

(c)

Figure 5. (a) Sampling of volatile chemicals on the forearm and back of the hand before and after cigarette smoking or exposure to second hand smoke (SHS). (b) Wrist (left) and ankle (right) sampling using a PDMS loop passive sampling device. (c) c.1-2 bags used for transport that were attached to track participant ID and exposure time in the occupational deployments; c.3 single wristband deployment. Reproduced from [75,77,78], with permission from Elsevier and ACS Publishing, 2019.

\subsubsection{Other Wearable Headspace Extractive Samplers}

Unconventional headspace extractive samplers including PDMS tubing sampling loops and silicone wristbands have been suggested in several studies for qualitative monitoring purposes. For instance, Roodt et al. used PDMS tubing in a study investigating the relationship between skin microbiome and anthropophilic mosquito disease vectors [77]. PDMS tubing was cut (180 and $240 \mathrm{~mm}$ tubing length, $0.25 \mathrm{~mm}$ inner diameter) to manufacture sampler loops (Figure $5 \mathrm{~b}$ ). The flexible nature of PDMS tubing allowed samplers to be employed in non-conventional sampling areas, in the wrists and ankles of the participants. Among the wide range of extracted analytes, 88 were identified in total, several of which, most notably cyclic ketones, were not previously reported in skin volatile literature. As an exemplary application area, the correlation between human skin microbiome and the attractiveness of participants to anthropophilic blood host seeking mosquitoes were investigated. Identification of previously unreported skin VOCs indicates that such passive sampling devices have not yet reached their full potential and can be explored to sample from unconventional skin areas. Another recent study using silicone wristbands was able to demonstrate the applicability of wearable extractive devices for monitoring of occupational exposure of roofers to chemical compounds released during hot asphalt application [78]. The obtained results indicated that the silicone wristbands were able to absorb 25 polycyclic aromatic hydrocarbons (PAHs) during $8 \mathrm{~h}$ of exposure under working 
conditions as well as differentiate the variations in the amounts of the PAH collected in divergent environmental condition, suggesting its applicability for sensitive monitoring. The silicone bands can be seen above in Figure 5c. PDMS tubing sampling loops and silicone wristbands represent the quintessential wearable sampling devices in the sense that they are simple, practical, robust devices that have the capability to be fine-tuned by surface or bulk material functionalization. The possibility of functionalization could allow these types of devices to either be used to target a specific range of analytes in terms of polarity, size, and volatility or to increase their extractive range to be used in untargeted studies. However, it should be kept in mind that these devices are completely open to the environment; therefore, a high background signal should be expected.

A summary of recent non-invasive skin sampling techniques, devices, and their applications can be found below in Table 2 . 
Table 2. Summary of reviewed skin sampling methods.

\begin{tabular}{|c|c|c|c|c|c|c|}
\hline Method & Materials & Body Part & Analytes & Sampling Time & Instrumentations & Comments \\
\hline Patch type [34] & PDMS & $\begin{array}{l}\text { Upper back, forearms, } \\
\text { back thigh }\end{array}$ & VOCs & $1 \mathrm{~h}$ & GC-MS & $\begin{array}{l}\text { "sandwich membrane", } \\
\text { minimal contamination }\end{array}$ \\
\hline Patch type [36] & PDMS & Armpit & $\begin{array}{c}\text { Fatty acid metabolites, } \\
\text { VOCs }\end{array}$ & $30 \mathrm{~min}$ & TD-SESI-MS/TD-GC-MS & suitable for automation \\
\hline Patch type [38] & PDMS & Forehead & VOCs & $30 \mathrm{~min}$ & TD-GC-MS & $\begin{array}{c}\text { complementary to breath } \\
\text { analysis }\end{array}$ \\
\hline Patch type [35] & PDMS & Ear & $\begin{array}{l}\text { Rabbit skin } \\
\text { metabolites, ulcer } \\
\text { metabolites }\end{array}$ & $30 \mathrm{~min}$ & GC-MS & rabbit model study \\
\hline Patch type [40] & PDMS & Foot & VOCs & $30 \mathrm{~min}$ & TD-GC-MS & $\begin{array}{c}\text { complementary to bacterial } \\
\text { mapping }\end{array}$ \\
\hline Patch type [42] & Agarose hydrogel & Lower arm & Skin metabolites & $1 \mathrm{~min}-3 \mathrm{~h}$ & nanoDESI-MS & direct mass spectrometry \\
\hline Patch type [44] & Agarose hydrogel & $\begin{array}{l}\text { Upper and lower } \\
\text { limbs, abdomen, back }\end{array}$ & $\begin{array}{l}\text { Psoriatic skin } \\
\text { metabolites }\end{array}$ & $20 \mathrm{~min}$ & nanoDESI-MS & direct mass spectrometry \\
\hline Patch type [43] & Agarose hydrogels & Lower arm & $\begin{array}{c}\text { Topical drug } \\
\text { metabolites, nicotine } \\
\text { and scopolamine } \\
\text { metabolites }\end{array}$ & $10 \mathrm{~min}$ & nanoDESI-MS & direct mass spectrometry \\
\hline Microneedle [53] & Polylactic acid & Mouse skin & Skin biomarkers & $1 \mathrm{~h}$ & $\begin{array}{c}\text { microplate UV/VIS } \\
\text { spectrophotometry, } \\
\text { densitometric analysis }\end{array}$ & $\begin{array}{c}\text { limited to biomarkers with } \\
\text { known antibodies, can only } \\
\text { sample from specific skin } \\
\text { depth }\end{array}$ \\
\hline Headspace [63] & $\begin{array}{c}\text { DVB/carboxen/PDMS } \\
\text { (Stableflex) }\end{array}$ & Volar forearm & VOCs & $15 \mathrm{~min}$ & GC-MS & glass housing \\
\hline Headspace [64] & $\begin{array}{c}\text { DVB/carboxen/PDMS } \\
\text { (Stableflex) }\end{array}$ & Volar forearm & $\begin{array}{c}\text { Skin and } \\
\text { fragrance-derived } \\
\text { VOCs }\end{array}$ & $5-40 \mathrm{~min}$ & GC-MS & glass housing \\
\hline Passive sampling [77] & PDMS & Wrist, ankle & $\begin{array}{l}\text { Skin VOCs, mosquito } \\
\text { semiochemicals }\end{array}$ & $4 \mathrm{~h}$ & $\mathrm{GC} \times \mathrm{GC}-\mathrm{TOFMS}$ & $\begin{array}{l}\text { controlled environment is } \\
\text { recommended for good } \\
\text { repeatability }\end{array}$ \\
\hline
\end{tabular}


Table 2. Cont.

\begin{tabular}{|c|c|c|c|c|c|c|}
\hline Method & Materials & Body Part & Analytes & Sampling Time & Instrumentations & Comments \\
\hline $\begin{array}{l}\text { Passive flux } \\
\text { sampling [73] }\end{array}$ & MonoTrap ${ }^{\circledR}$ DCC18 & $\begin{array}{l}\text { Forearm, thigh, calf, } \\
\text { forehead, neck, } \\
\text { abdomen }\end{array}$ & 2-nonenal, diacetyl & $7 \mathrm{~h}$ & GC-MS & $\begin{array}{l}\text { flux flow knowledge is } \\
\text { required for quantitation }\end{array}$ \\
\hline $\begin{array}{c}\text { Passive flux } \\
\text { sampling [74] }\end{array}$ & $\begin{array}{l}\text { Conditioned cellulose } \\
\text { paper }\end{array}$ & see Figure 4 & Ammonia & $1 \mathrm{~h}$ & Ion chromatography & $\begin{array}{l}\text { flux flow knowledge is } \\
\text { required for quantitation }\end{array}$ \\
\hline $\begin{array}{l}\text { Passive flux } \\
\text { sampling [75] }\end{array}$ & MonoTrap ${ }^{\circledR}$ DCC18 & $\begin{array}{l}\text { Forearm, back of the } \\
\text { hand }\end{array}$ & VOCs & $1 \mathrm{~h}$ & GC-MS & $\begin{array}{l}\text { flux flow knowledge is } \\
\text { required for quantitation }\end{array}$ \\
\hline Passive sampling [78] & Silicone & Wrist & $\begin{array}{l}\text { PAHs, environmental } \\
\text { chemicals }\end{array}$ & $2-24 \mathrm{~h}$ & GC-MS & low repeatability \\
\hline
\end{tabular}




\section{Oral Fluid and Ocular Surface Sampling}

As summarized above, most of the research including wearable extractive devices has focused on detection of skin related analytes. Studies discussed above were mostly focused on implementing already existing tools/extractive materials directly for skin sampling, neglecting other possible matrices that can be used to gather biological information. In fact, saliva and ocular surfaces can be sampled easily and could provide unique information about a biological system. However, as it has been shown below, the potential of wearable devices for those matrices have not been thoroughly explored yet.

\subsection{Saliva Sampling}

Saliva sampling has been gathering interest as an alternative sampling matrix to blood and urine for forensic applications, disease biomarkers, drug and doping control, and flavor studies amongst other niche areas. One of the main reasons why saliva is an attractive alternative is that the samples can be collected relatively easy without privacy concerns which are especially important in doping tests. Saliva is commonly sampled through draining, spitting, and contact sampling with commercial products such as Salivette ${ }^{\circledR}$ or Drugwipe ${ }^{\circledR}$, and by chewing inert materials [79-82]. Saliva sampling is inherently less invasive compared to some other biological specimens like blood or urine, and there is still potential for developing alternative methods applicable for in vivo sampling.

One advancement towards in vivo saliva analysis was realized by Bessonneau et al. employing thin film microextraction (TFME) with GC-MS and LC-MS techniques to evaluate and compare the ability of in vivo and ex vivo sampling, as well as the ability to determine prohibited substances in saliva [83]. In order to obtain maximum metabolite coverage two different type of extractive phases were used for salivary sampling. Hydrophilic lipophilic balanced (HLB) particles were embedded in PDMS to be used as the extractive phase for GC-MS analysis and HLB particles were embedded in polyacrylonitrile (PAN) to be used as extractive phase for LC-MS analysis. For in vivo sampling, TFME devices were placed under the tongue of participants for $5 \mathrm{~min}$ and then extracted analytes on the HLB-PDMS phase were desorbed directly to GC-MS using a high volume thermal desorption unit while extracted analytes on HLB-PAN phase were first desorbed into a suitable solvent prior to their LC-MS analysis. The same desorption protocol was followed for $5 \mathrm{~min}$ ex vivo sampling from $1 \mathrm{~mL}$ of collected saliva. Comparison of ex vivo to in vivo studies revealed similar results for hydrophilic compounds while higher peak intensities were observed for in vivo sampling for hydrophobic compounds. This is a reasonable result since hydrophobic compounds tend to have secondary interactions with labware. This study highlights the advantage of employing in vivo sampling if hydrophobic compounds are of interest and secondary interactions can potentially disrupt sampling. Moreover, in vivo sampling may provide the unique advantage of capturing short lived metabolites that are susceptible to decomposition which can be difficult to be determined with other methods.

\subsection{Oral Tissue Sampling}

Chen et al. developed a different approach for oral sampling by using a moving string sampling probe for in situ endoscopic MS of a living mouse and to take samples from oral surfaces [84]. The device consists of a disposable cotton sampling string, which moves through the sampling area. The string is smeared and carries a small amount of tissue samples that adhere to its surface directly to an ionization source to be subsequently analyzed by MS. Figure 6 depicts the schematic of the sampling device. In the study, the sampling probe was attached to an industrial endoscope with a camera and miniature super-bright LED. A metallic tube was bent into a V-shape and partially cut to expose the sampling strip, with the authors noting that the camera allows the sampling process to be monitored in real-time which can be recorded if desired. In this study, the samples were taken from the surface of the tongue of a volunteer who had consumed a caffeinated beverage. Both atmospheric pressure chemical ionization (APCI) and ESI mass spectra showed a strong peak at $\mathrm{m} / \mathrm{z} 195.09\left([\text { Caffeine }+\mathrm{H}]^{+}\right.$) and two peaks at $\mathrm{m} / \mathrm{z}$ values $116.07\left(\left[\mathrm{C}_{5} \mathrm{H}_{9} \mathrm{NO}_{2}+\mathrm{H}\right]^{+}\right)$and $118.09\left(\left[\mathrm{C}_{5} \mathrm{H}_{11} \mathrm{NO}_{2}+\mathrm{H}\right]^{+}\right)$which were tentatively 
identified as proline and valine respectively. This further affirms the capability of this method to be used for sampling small molecules such as amino acids. The proof-of-concept setup designed by the investigators employed a cotton string and APCI/ESI-MS. The moving string approach can be realized with any type string, as the authors mention, and with any type of ionization setup after necessary changes are made. Although not used in the study for such purpose, employing a camera to record the sampling process makes it possible to generate a spatial metabolite map of the sampling area to provide an additional layer of information.

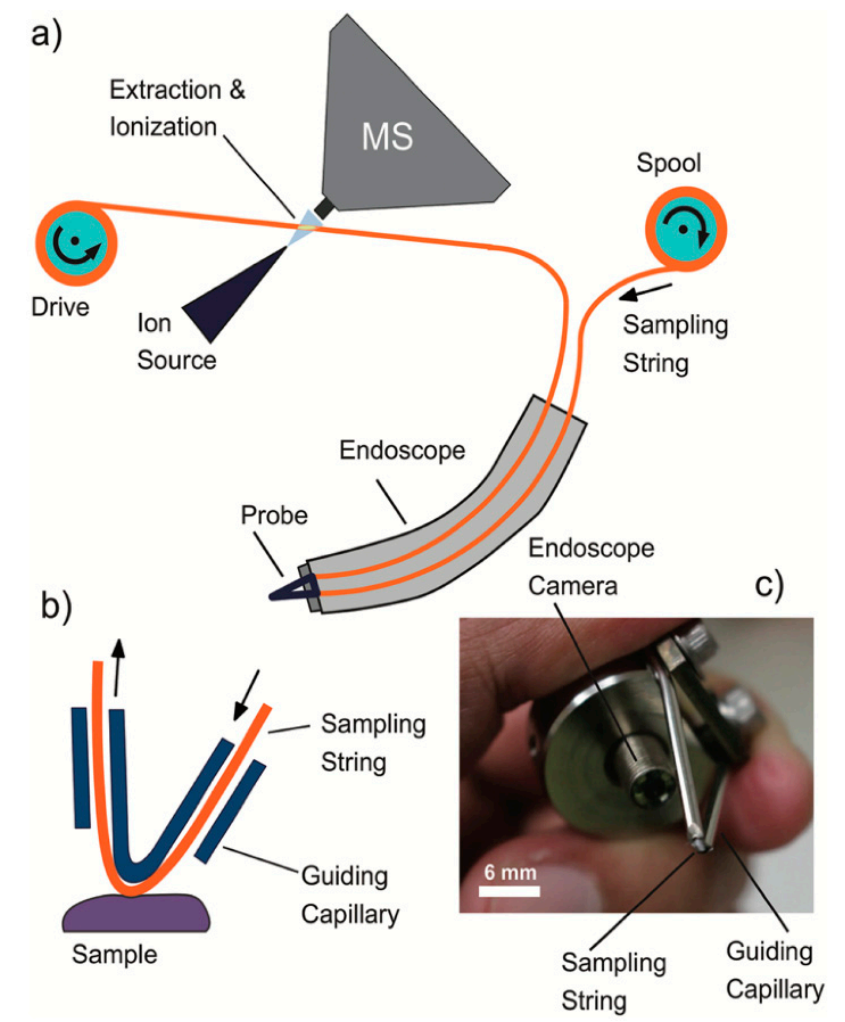

Figure 6. (a) Simplified schematic of the endoscopic mass spectrometry system that uses a moving string as the sampling and transportation material. (b) Configuration of the sampling probe. The sample is wiped off from the surface by the moving string and carried to the extraction and ionization region near the mass spectrometry (MS) inlet. (c) Photograph of the probe tip. Reproduced from [84], with permission from RSC Publishing, 2019.

\subsection{Ocular Surface Sampling}

The human eye is an extremely intricate and complex organ that consists of many distinct parts with distinct characteristics and qualities that are unique in the human body. Seemingly small disruptions to this delicate system can cause visual impairment and discomfort. It has been an ongoing effort to identify and investigate the non-redundant proteins in the human eye, the most notable effort being The Human Eye Proteome Project launched in 2013 [85]. Diagnosis of ocular infections caused by bacteria, fungi, parasites, or viruses is another area of research where there is an interest in developing new clinical tools [86]. A recent study in 2018 conducted by the association for Research in Vision and Ophthalmology (AVRO) reported that $43 \%$ of researchers find it "difficult" or "very difficult" to obtain human eye tissue, and $43 \%$ of the participants stated that they regularly limit the scope of their work due to inability of finding eye tissue that meets the needs of their research [87]. Therefore, it is of paramount importance to develop new tools to sample compounds from the human eye to tackle the problems researchers face in this area, which can greatly benefit from the advancements in low- and non-invasive sampling techniques. 
Such an attempt was made by Liou et al. in a study to sample from the eyelids of volunteers using a watercolor brush to profile caffeine and its metabolites [88]. The ethanol-soaked tip of the watercolor brush was simply rubbed against eyelids of 4 volunteers who had consumed three cups of coffee with $3 \mathrm{~h}$ interval between each cup. After sampling, the brush was moved in front of the inlet of the MS instrument. The analytes evaporated from the brush surface by the aid of the ethanol and then subsequently ionized by charged ESI plum before finally being detected by the instrument. The intensity of the ions and the distance of the brush to the ESI needle were investigated, with the findings summarized in Figure 7. Although the authors chose to sample from the eyelid because of the high concentration of blood vessels in the area and the natural trapping properties of eyelashes and not because of any intention to sample eye-related metabolites or compounds, the sampling concept can still be applied to detect eye related metabolites and compounds as the detection of caffeine metabolites indicates. It should also be noted that ethanol which was used to soak the tip of the brush could extract many unwanted skin matrix components and environmental contaminants resulting in high matrix effect during such direct-to-MS approaches.

(A)

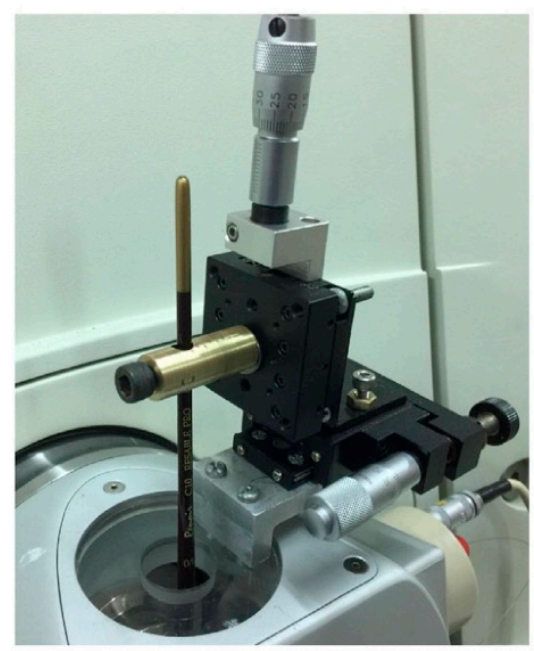

(B)

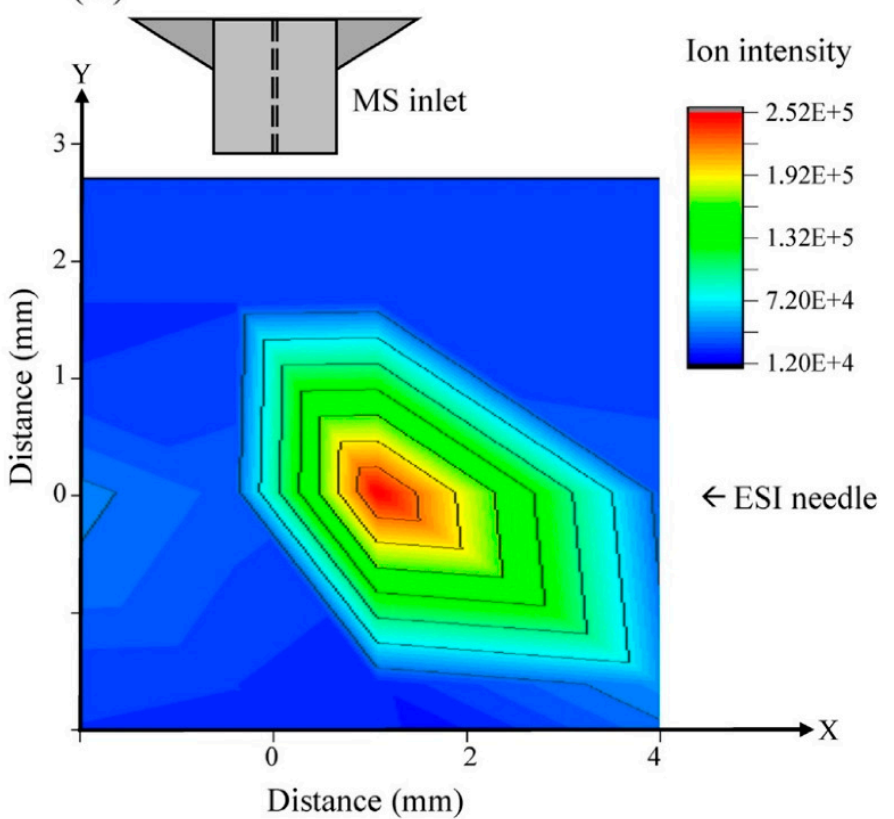

Figure 7. Photo (A), a picture of the sampling brush-spray ionization/mass spectrometry set up used in this study. The sampling brush was located between the mass inlet and the ESI needle (not shown in the picture). (B) relationship between ion intensities and the location of the brush. In this case, caffeine was used as the test sample (concentration levels, $10 \mu \mathrm{g} \mathrm{mL}^{-1}$ ) and the ESI voltage was $+4.5 \mathrm{kV}$. The position, indicated in red, denotes the optimized location. Reproduced from [88], with permission from Elsevier, 2019.

An interesting study, which could act as a lighthouse to steer future research, was conducted by Lopez et al. where a hydrogel contact lens was developed to slow the progression of corneal blindness caused by overexpression of zinc-dependent matrix metalloproteinases (MMPs) [89]. Monomer of poly(2-hydroxyetyl methacrylate) (pHEMA) were modified before polymerization with dipicolylamine (DPA) to synthesize the pDPA-HEMA hydrogel. DPA has a selective binding affinity toward zinc ions (up to $K_{d}=1 \times 10^{-11} \mathrm{M}$ [90]) which is essential for MMPs to function. Removal of zinc by the pDPA-HEMA hydrogel contact lens deactivates MMPs and slows down the degradation of the cornea. As summarized in Figure 8, ex vivo studies using porcine cornea to simulate human cornea were conducted by the authors which demonstrated advantageous results compared to conventional treatments. Because there is no systemic circulation of zinc targeting drugs in the body, the treatment 
is targeted and limited to the cornea only. In addition, DPA only selectively binds to zinc out of all biologically active metal ions excluding the possibility of side effects. Although this study is not directly related to the ocular surface sampling, it is vital to show the potential of using such biocompatible functionalized materials for extracting biological information directly in vivo from the ocular surface.

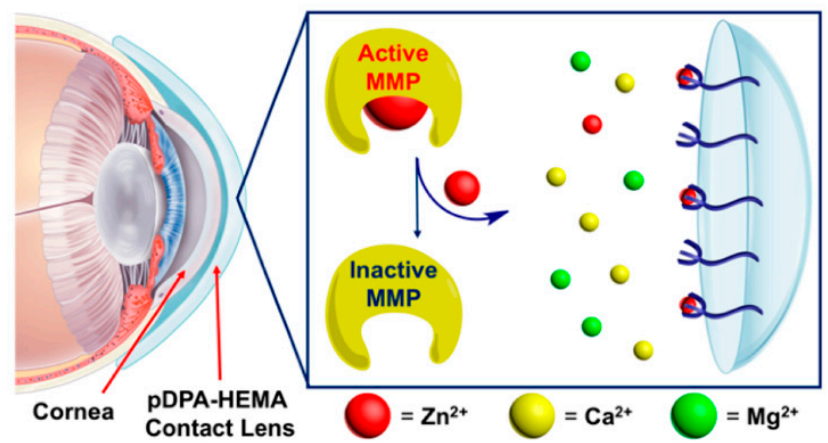

Figure 8. Schema of deactivation of matrix metalloproteinases (MMPs) by the dipicolylaminepoly(2-hydroxyetyl methacrylate (pDPA-HEMA)-based contact lens. Reproduced from [89], with permission from ACS Publications, 2019.

\section{Extractive Patches for Imaging Applications}

Recently, ambient mass spectrometric (AMS) imaging techniques have gained popularity in many areas of research providing insights for metabolomics and lipidomic differences between samples, the discovery of biomarkers creating these differences, and associated clinical applications. However, as can be predicted, these techniques when applied directly to the samples may experience high background, or ionization suppression which decreases the sensitivity of the analysis. Therefore, involvement of suitable sample preparation methods for surface imaging using direct-to-MS approaches are becoming more and more crucial. With this intention, Hemalatha et al. imprinted patterns of printing inks, plant parts, and fungal growth on electrospun nanofiber mats and employed desorption electrospray ionization mass spectrometry (DESI-MS) to rapidly analyze and capture images of the imprinted patterns and analyte droplets [91]. Nanofiber mats were electrospun from a solution of Nylon-6 dissolved in formic acid and characterized by SEM. Patterns were produced on the electrospun mats by either imprinting in the case of plant slices and ink-printed patterns or by dispersing a single drop of selected analyte directly on top of the mat. Imprinted mats were then "scanned" using a 2D moving stage with a $250 \mu \mathrm{m}$ step distance. In a typical experiment, a spray of charged solvent was pointed to the surface of the imprinted mat. The charged solvent dissolves the compounds and ionizes them similar to electrospray ionization (ESI). Subsequently, the generated molecular ions were transferred to a MS for detection. The images of the samples were obtained by raster scanning the mats under the DESI spray and detection of the molecular ions at each spot. Major metabolites of several plants, analytes, and constituents of dyes were detected and their imprints were imaged, some of the results can be seen in Figure 9 . 

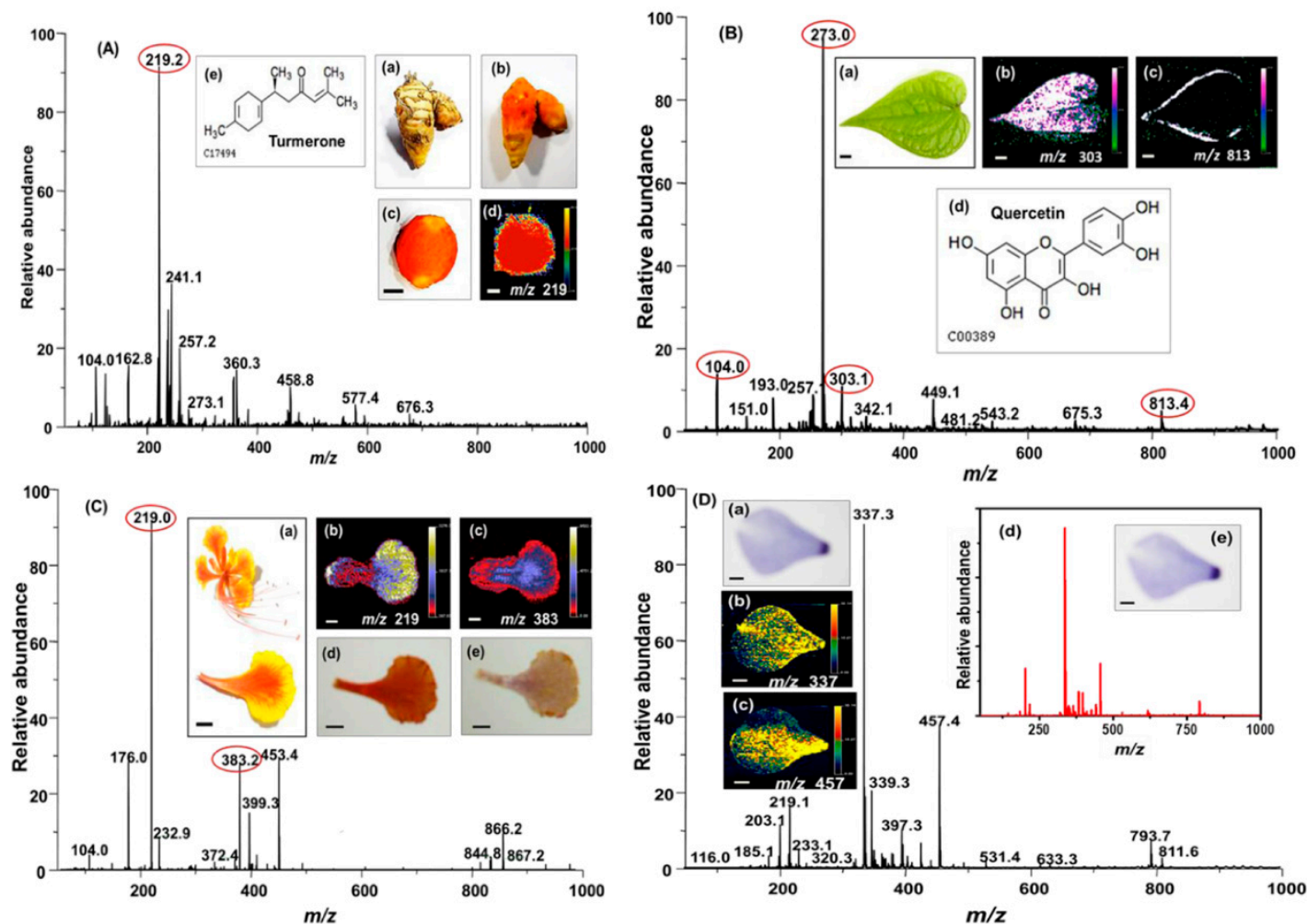

Figure 9. (a) Desorption electrospray ionization mass spectrometry (DESI-MS) spectrum from a turmeric rhizome slice of an imprinted nylon nanofiber mat. $(\mathbf{a}, \mathbf{b})$ Optical images of a whole and unskinned turmeric rhizome. (c) Imprinted slice on a nylon nanofiber mat. (d) DESI-MS image at m/z 219 due to $\alpha$-turmerone shown. Reproduced from [91], with permission from ACS Publications, 2019.

Li et al. utilized a different imprinting (extractive) media using a similar approach by developing a solid-phase extraction device employing micro-funnels to scan the image of an imprinted strawberry as a proof of concept [92]. In order to functionalize the micro-funnel membrane Parafilm $\mathrm{M}^{\circledR}$ and Teflon tape with silicone adhesive was used to fix a mask with a chosen pattern on the surface, and C18 functionalized silicate powder was used to create grooves on the membrane with extractive micro-funnels. Figure 10 shows the workflow of the preparation and analysis of the micro-funnel based SPE device as well as the mapping of major metabolites found in the imprinted strawberry slice. Although both approaches are good candidates to decrease background signal in direct-to-MS studies, the effect of imprinting in chemical image resolution is not discussed thoroughly. In fact, limited image resolution should be expected, mainly due to diffusion phenomenon. The diffusion of analytes in the extractive phase during the chemical imprinting and further diffusion of analyte during the desorption process will be the main reasons for limited resolution. Also, it should be kept in mind that none of these imaging studies were performed directly in situ on living systems. However, they show the potential of the current progress in imprint imaging with MS towards the applicability of wearable extractive devices for non-destructive in vivo and in situ small molecule imaging. 


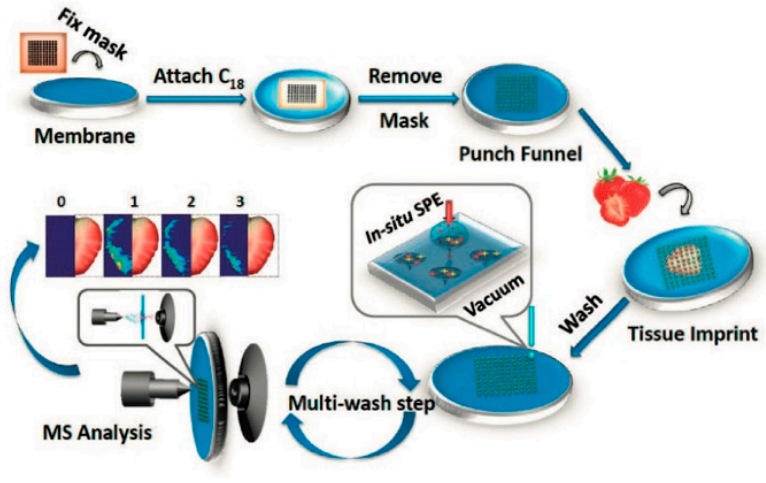

(a)

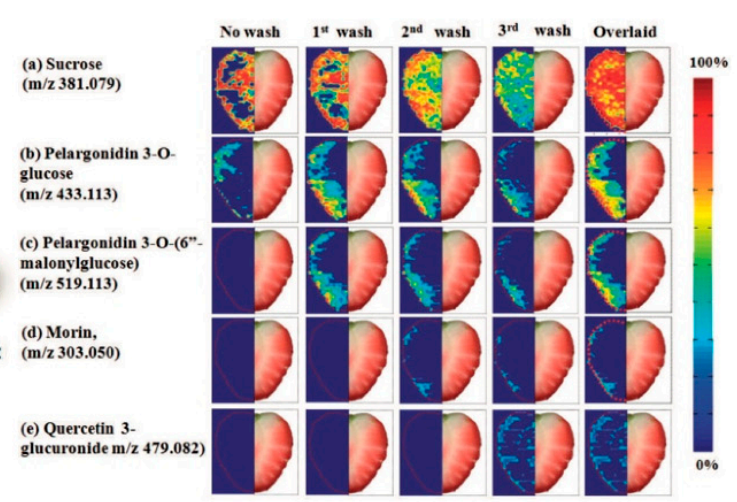

(b)

Figure 10. (a) Flow chart of C18-mounted solid phase extraction (SPE) micro-funnel-based spray for Ion-mobility spectrometry (IMS). (b) Chemical images of major components of a strawberry using C18-mounted SPE micro-funnel based spray MS with 0-3 washing steps. Reproduced from [92], with permission from SAGE, 2019.

\section{Perspectives in Future Directions and Concluding Remarks}

The goal of this review was to summarize the current technology that has been paving the way for novel applications for non-invasive in situ sampling devices and highlighting potential methods that can be used for wearable extraction-based devices. There are two routes of progress in this area. The first is focused on collection methods of the representative specimen in a non-invasive way from the investigated system, with very little technological improvement in collection devices. The second and more important aspect is the development of wearable extractive devices which are designed to allow free movement of the object during the sampling period with the advantage of integrating the sampling and sample preparation into a single step. This approach in general allows short sampling times with information relevant to the current state of the system, and long-term monitoring providing insightful information about time weighted average (TWA) concentration of the species in the studied system. In this review we focused only on non-invasive extractive sampling tools and wearable devices that can be used in various areas, including clinical application, exposure monitoring, food quality control, and cosmetics. A brief overview of the methods and their advantages as well as their shortcomings is shown in Table 3. The current progress in the area is promising; however, only a fraction of the full potential of such devices is currently being developed and investigated. It is clear that with current direction of the development in noninvasive wearable technologies, soon many different areas will start to use the advantage of these technologies.

Table 3. Comparison of reviewed sampling methods (biocompatibility, non-invasiveness, and

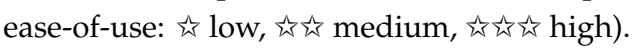

\begin{tabular}{|c|c|c|c|c|c|c|}
\hline Method & Biocompatibility & Non-Invasiveness & Ease-of-Use & $\begin{array}{l}\text { Commercial } \\
\text { Availability }\end{array}$ & $\begin{array}{c}\text { Sampler to } \\
\text { Instrument } \\
\text { Coupling }\end{array}$ & $\begin{array}{l}\text { Real Time } \\
\text { Monitoring }\end{array}$ \\
\hline PDMS patches & 武地罂 & 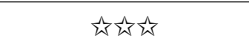 & 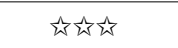 & Yes $^{c}$ & Yes $^{\mathrm{f}}$ & No \\
\hline $\begin{array}{l}\text { Hydrogel } \\
\text { patches }\end{array}$ & 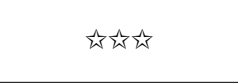 & 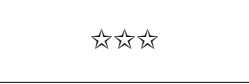 & 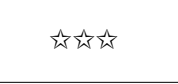 & No & Yes & No \\
\hline $\begin{array}{l}\text { Microneedle } \\
\text { arrays }\end{array}$ & 战能 & 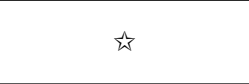 & 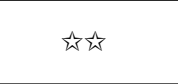 & No & No & No \\
\hline $\begin{array}{c}\text { SPME } \\
\text { headspace } \\
\text { sampler }\end{array}$ & 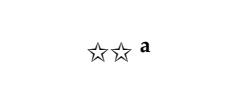 & 地方公 & 必 & Yes $^{\mathrm{d}}$ & Yes & No \\
\hline
\end{tabular}


Table 3. Cont.

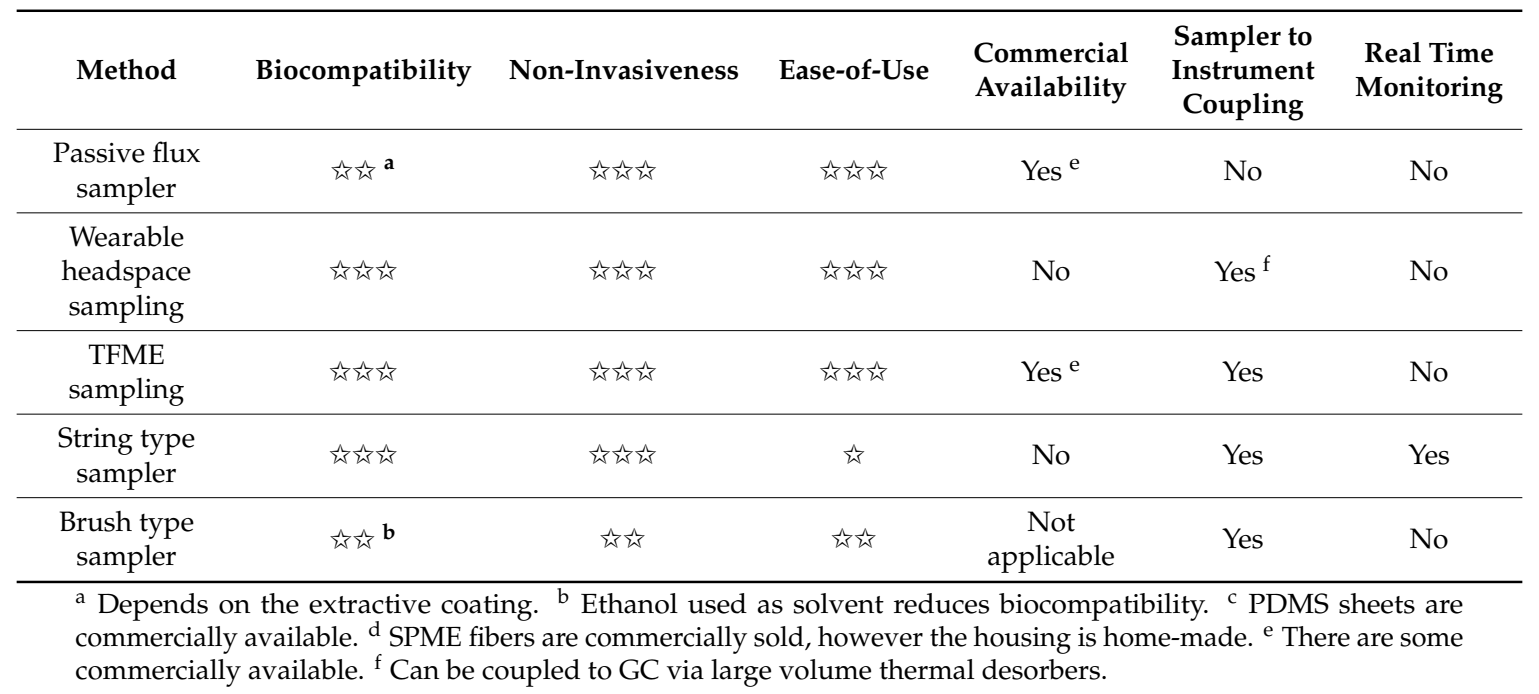

For instance, doping control could be one of the areas that could benefit from the wearable extractive patches. Such patches will protect athletes' privacy during the sample collection process as it does not require any assistance for the sampling. Currently, there are some wearable patches that are being considered for sweat sampling; however, their main target is to collect the sweat itself rather than to focus on extraction of analytes that may be present in the sweat, giving the information about drug abuse or other type of doping.

Another area that such patches will benefit is roadside sampling. Particularly if it is combined with a portable device it might benefit opioid and cannabinoid analysis. Taking in to account that marijuana has been legalized in some countries, it is necessary to have tools that can be employed by law enforcement to perform fast roadside tests compatible with portable detection systems.

As can be seen from this review all current sampling devices are focused on skin and sweat sampling. However, alternative matrices such as ocular surface and oral fluids/surface have high potential for information as many sensor-based wearable devices have been developed.

Exposomics is another area that has a great potential to use such devises, especially for evaluation of hazards arising from occupational and environmental exposure to various chemicals that are detrimental to human health. There are already some early studies in this area using extractive wearable devices to investigate human exposure to environmental chemicals. However, more research is needed, and wearable extractive devices will be one of the main tools in the analytical toolbox for exposomic studies.

Moreover, such devices will facilitate the development of protocols for hazard analysis at critical control points. One of these areas would be pesticide control in agricultural products. Because of their frequent uncontrolled use in agricultural products, pesticide residues accumulate in food which often is associated with various health problems. There are many methods developed for pesticide analysis; however, there is still a high demand for novel and reliable methods applicable to multi-residue analyses on-site. Such extractive devices can be used for pesticide profiling on fruits and vegetables during the growth which will allow regulation of the safe amount of pesticides used in the production.

There is also a reasonable demand for wearable devices with different selectivity targeting specific needs. In the near future, the current developments in nanotechnology and nanostructured materials and the synthesis of novel extractive phase will allow the properties of materials to be tuned towards enhancing the selectivity towards targeted analytes. Potentially promising smart selective materials can be summarized as, but not limited to, molecularly imprinted polymeric materials, aptamer-based surface modifications, and metal-organic frameworks. 
Finally, more work will be done in future for coupling these extractive wearable devices with portable instrumentation for direct sampling and monitoring on site.

Author Contributions: A.A.N.: Literature review, writing and revisions. E.B.: Editing, review and revisions. Funding: This research received no external funding.

Acknowledgments: The authors would like to thank Daniel Rickert for his help in the proofreading and editing of the manuscript.

Conflicts of Interest: The authors declare no conflict of interest.

\section{References}

1. Shim, B.S.; Chen, W.; Doty, C.; Xu, C.; Kotov, N.A. Smart Electronic Yarns and Wearable Fabrics for Human Biomonitoring made by Carbon Nanotube Coating with Polyelectrolytes. Nano Lett. 2008, 8, 4151-4157. [CrossRef] [PubMed]

2. Amjadi, M.; Pichitpajongkit, A.; Lee, S.; Ryu, S.; Park, I. Highly Stretchable and Sensitive Strain Sensor Based on Silver Nanowire-Elastomer Nanocomposite. ACS Nano 2014, 8, 5154-5163. [CrossRef] [PubMed]

3. Gao, W.; Emaminejad, S.; Nyein, H.Y.Y.; Challa, S.; Chen, K.; Peck, A.; Fahad, H.M.; Ota, H.; Shiraki, H.; Kiriya, D.; et al. Fully integrated wearable sensor arrays for multiplexed in situ perspiration analysis. Nature 2016, 529, 509-514. [CrossRef]

4. Amjadi, M.; Kyung, K.-U.; Park, I.; Sitti, M. Stretchable, Skin-Mountable, and Wearable Strain Sensors and Their Potential Applications: A Review. Adv. Funct. Mater. 2016, 26, 1678-1698. [CrossRef]

5. Trung, T.Q.; Lee, N.-E. Flexible and Stretchable Physical Sensor Integrated Platforms for Wearable Human-Activity Monitoringand Personal Healthcare. Adv. Mater. 2016, 28, 4338-4372. [CrossRef] [PubMed]

6. Penn, D.J.; Oberzaucher, E.; Grammer, K.; Fischer, G.; Soini, H.A.; Wiesler, D.; Novotny, M.V.; Dixon, S.J.; $\mathrm{Xu}$, Y.; Brereton, R.G. Individual and gender fingerprints in human body odour. J. R. Soc. Interface 2007, 4, 331-340. [CrossRef]

7. Nemes, P.; Vertes, A. Ambient mass spectrometry for in vivo local analysis and in situ molecular tissue imaging. Trac.-Trends Anal. Chem. 2012, 34, 22-34. [CrossRef]

8. Dormont, L.; Bessière, J.-M.; Cohuet, A. Human Skin Volatiles: A Review. J. Chem. Ecol. 2013, 39, 569-578. [CrossRef]

9. Andrisic, L.; Dudzik, D.; Barbas, C.; Milkovic, L.; Grune, T.; Zarkovic, N. Short overview on metabolomics approach to study pathophysiology of oxidative stress in cancer. Redox Biol. 2017, 14, 47-58. [CrossRef]

10. Noël, F.; Piérard-Franchimont, C.; Piérard, G.E.; Quatresooz, P. Sweaty skin, background and assessments. Int. J. Dermatol. 2012, 51, 647-655. [CrossRef]

11. Prada, A.; Furton, K.G. Recent Advances in Solid-Phase Microextraction for Forensic Applications. In Comprehensive Sampling and Sample Preparation; Pawliszyn, J., Ed.; Academic Press: Oxford, UK, 2012; pp. 877-891.

12. Curran, A.M.; Prada, P.A.; Furton, K.G. Canine human scent identifications with post-blast debris collected from improvised explosive devices. Forensic Sci. Int. 2010, 199, 103-108. [CrossRef] [PubMed]

13. DeGreeff, L.E.; Furton, K.G. Collection and identification of human remains volatiles by non-contact, dynamic airflow sampling and SPME-GC/MS using various sorbent materials. Anal. Bioanal. Chem. 2011, 401, 1295-1307. [CrossRef] [PubMed]

14. Prugnolle, F.; Lefèvre, T.; Renaud, F.; Møller, A.P.; Missé, D.; Thomas, F. Infection and body odours: Evolutionary and medical perspectives. Infect. Genet. Evol. 2009, 9, 1006-1009. [CrossRef] [PubMed]

15. Kim, K.-H.; Jahan, S.A.; Kabir, E. A review of breath analysis for diagnosis of human health. TrAC Trends Anal. Chem. 2012, 33, 1-8. [CrossRef]

16. Santonico, M.; Lucantoni, G.; Pennazza, G.; Capuano, R.; Galluccio, G.; Roscioni, C.; La Delfa, G.; Consoli, D.; Martinelli, E.; Paolesse, R.; et al. In situ detection of lung cancer volatile fingerprints using bronchoscopic air-sampling. Lung Cancer 2012, 77, 46-50. [CrossRef] [PubMed]

17. Saudan, C.; Baume, N.; Robinson, N.; Avois, L.; Mangin, P.; Saugy, M. Testosterone and doping control. Br. J. Sports Med. 2006, 40, i21-i24. [CrossRef] [PubMed] 
18. Geyer, H.; Schänzer, W.; Thevis, M. Anabolic agents: Recent strategies for their detection and protection from inadvertent doping. Br. J. Sports Med. 2014, 48, 820-826. [CrossRef]

19. Xu, X.; Weisel, C.P. Dermal uptake of chloroform and haloketones during bathing. J. Expo. Anal. Environ. Epidemiol. 2005, 15, 289-296. [CrossRef]

20. Jiřík, V.; Machaczka, O.; Miturová, H.; Tomášek, I.; Šlachtová, H.; Janoutová, J.; Velická, H.; Janout, V. Air Pollution and Potential Health Risk in Ostrava Region-A Review. Cent. Eur. J. Public Health 2016, 24, S4-S17. [CrossRef]

21. Vineis, P.; Chadeau-Hyam, M.; Gmuender, H.; Gulliver, J.; Herceg, Z.; Kleinjans, J.; Kogevinas, M.; Kyrtopoulos, S.; Nieuwenhuijsen, M.; Phillips, D.H.; et al. The exposome in practice: Design of the EXPOsOMICS project. Int. J. Hyg. Environ. Health 2017, 220, 142-151. [CrossRef]

22. Taylor, R.P.; Polliack, A.A.; Bader, D.L. The Analysis of Metabolites in Human Sweat: Analytical Methods and Potential Application to Investigation of Pressure Ischaemia of Soft Tissues. Ann. Clin. Biochem. Int. J. Biochem. Lab. Med. 1994, 31, 18-24. [CrossRef] [PubMed]

23. Kutyshenko, V.P.; Molchanov, M.; Beskaravayny, P.; Uversky, V.N.; Timchenko, M.A. Analyzing and Mapping Sweat Metabolomics by High-Resolution NMR Spectroscopy. PLoS ONE 2011, 6, e28824. [CrossRef] [PubMed]

24. Shirreffs, S.M.; Maughan, R.J. Whole body sweat collection in humans: An improved method with preliminary data on electrolyte content. J. Appl. Physiol. 1997, 82, 336-341. [CrossRef] [PubMed]

25. Gallagher, M.; Wysocki, C.J.; Leyden, J.J.; Spielman, A.I.; Sun, X.; Preti, G. Analyses of volatile organic compounds from human skin. Br. J. Dermatol. 2008, 159, 780-791. [CrossRef]

26. Calderón-Santiago, M.; Priego-Capote, F.; Jurado-Gámez, B.; Luque de Castro, M.D. Optimization study for metabolomics analysis of human sweat by liquid chromatography-tandem mass spectrometry in high resolution mode. J. Chromatogr. A 2014, 1333, 70-78. [CrossRef]

27. Kintz, P.; Cirimele, V.; Ludes, B. Detection of Cannabis in Oral Fluid (Saliva) and Forehead Wipes (Sweat) from Impaired Drivers. J. Anal. Toxicol. 2000, 24, 557-561. [CrossRef]

28. Wang, L.; Pi, Z.; Liu, S.; Liu, Z.; Song, F. Targeted metabolome profiling by dual-probe microdialysis sampling and treatment using Gardenia jasminoides for rats with type 2 diabetes. Sci. Rep. 2017, 7, 10105. [CrossRef]

29. Poole, J.J.; Grandy, J.J.; Yu, M.; Boyaci, E.; Gómez-Ríos, G.A.; Reyes-Garcés, N.; Bojko, B.; Heide, H.V.; Pawliszyn, J. Deposition of a Sorbent into a Recession on a Solid Support to Provide a New, Mechanically Robust Solid-Phase Microextraction Device. Anal. Chem. 2017, 89, 8021-8026. [CrossRef]

30. Bruheim, I.; Liu, X.; Pawliszyn, J. Thin-Film Microextraction. Anal. Chem. 2003, 75, 1002-1010. [CrossRef]

31. Jiang, R.; Pawliszyn, J. Thin-film microextraction offers another geometry for solid-phase microextraction. TrAC Trends Anal. Chem. 2012, 39, 245-253. [CrossRef]

32. Souza-Silva, É.A.; Gionfriddo, E.; Shirey, R.; Sidisky, L.; Pawliszyn, J. Methodical evaluation and improvement of matrix compatible PDMS-overcoated coating for direct immersion solid phase microextraction gas chromatography (DI-SPME-GC)-based applications. Anal. Chim. Acta 2016, 920, 54-62. [CrossRef] [PubMed]

33. Risticevic, S.; Pawliszyn, J. Solid-Phase Microextraction in Targeted and Nontargeted Analysis: Displacement and Desorption Effects. Anal. Chem. 2013, 85, 8987-8995. [CrossRef] [PubMed]

34. Jiang, R.; Cudjoe, E.; Bojko, B.; Abaffy, T.; Pawliszyn, J. A non-invasive method for in vivo skin volatile compounds sampling. Anal. Chim. Acta 2013, 804, 111-119. [CrossRef] [PubMed]

35. Schivo, M.; Aksenov, A.A.; Pasamontes, A.; Cumeras, R.; Weisker, S.; Oberbauer, A.M.; Davis, C.E. A rabbit model for assessment of volatile metabolite changes observed from skin: A pressure ulcer case study. J. Breath Res. 2017, 11, 016007. [CrossRef]

36. Martin, H.J.; Reynolds, J.C.; Riazanskaia, S.; Thomas, C.L.P. High throughput volatile fatty acid skin metabolite profiling by thermal desorption secondary electrospray ionisation mass spectrometry. Analyst 2014, 139, 4279-4286. [CrossRef]

37. Lang, T.; Justenhoven, C.; Winter, S.; Baisch, C.; Hamann, U.; Harth, V.; Ko, Y.-D.; Rabstein, S.; Spickenheuer, A.; Pesch, B.; et al. The earwax-associated SNP c.538G>A (G180R) in ABCC11 is not associated with breast cancer risk in Europeans. Breast Cancer Res. Treat 2011, 129, 993-999. [CrossRef]

38. Martin, H.J.; Turner, M.A.; Bandelow, S.; Edwards, L.; Riazanskaia, S.; Thomas, C.L.P. Volatile organic compound markers of psychological stress in skin: A pilot study. J. Breath Res. 2016, 10, 046012. [CrossRef] 
39. Turner, M.A.; Bandelow, S.; Edwards, L.; Patel, P.; Martin, H.J.; Wilson, I.D.; Thomas, C.L.P. The effect of a paced auditory serial addition test (PASAT) intervention on the profile of volatile organic compounds in human breath: A pilot study. J. Breath Res. 2013, 7, 017102. [CrossRef]

40. Stevens, D.; Cornmell, R.; Taylor, D.; Grimshaw, S.G.; Riazanskaia, S.; Arnold, D.S.; Fernstad, S.J.; Smith, A.M.; Heaney, L.M.; Reynolds, J.C.; et al. Spatial variations in the microbial community structure and diversity of the human foot is associated with the production of odorous volatiles. FEMS Microbiol. Ecol. 2015, 91, 1-11. [CrossRef]

41. McHugh, D.J. Issue 288 of FAO fisheries technical paper. In Production and Utilization of Products from Commercial Seaweeds; Food and Agriculture Organization of the United Nations: Rome, Italy, 1987; p. 189.

42. Dutkiewicz, E.P.; Lin, J.-D.; Tseng, T.-W.; Wang, Y.-S.; Urban, P.L. Hydrogel Micropatches for Sampling and Profiling Skin Metabolites. Anal. Chem. 2014, 86, 2337-2344. [CrossRef]

43. Dutkiewicz, E.P.; Chiu, H.-Y.; Urban, P.L. Micropatch-arrayed pads for non-invasive spatial and temporal profiling of topical drugs on skin surface: Skin analysis. J. Mass Spectrom. 2015, 50, 1321-1325. [CrossRef] [PubMed]

44. Dutkiewicz, E.P.; Hsieh, K.-T.; Wang, Y.-S.; Chiu, H.-Y.; Urban, P.L. Hydrogel Micropatch and Mass Spectrometry-Assisted Screening for Psoriasis-Related Skin Metabolites. Clin. Chem. 2016, 62, 1120-1128. [CrossRef] [PubMed]

45. Kim, Y.-C.; Park, J.-H.; Prausnitz, M.R. Microneedles for drug and vaccine delivery. Adv. Drug Deliv. Rev. 2012, 64, 1547-1568. [CrossRef] [PubMed]

46. Tuan-Mahmood, T.-M.; McCrudden, M.T.C.; Torrisi, B.M.; McAlister, E.; Garland, M.J.; Singh, T.R.R.; Donnelly, R.F. Microneedles for intradermal and transdermal drug delivery. Eur. J. Pharm. Sci. 2013, 50, 623-637. [CrossRef] [PubMed]

47. Bhargav, A.; Muller, D.A.; Kendall, M.A.F.; Corrie, S.R. Surface Modifications of Microprojection Arrays for Improved Biomarker Capture in the Skin of Live Mice. ACS Appl. Mater. Interfaces 2012, 4, 2483-2489. [CrossRef]

48. Coffey, J.W.; Corrie, S.R.; Kendall, M.A.F. Early circulating biomarker detection using a wearable microprojection array skin patch. Biomaterials 2013, 34, 9572-9583. [CrossRef]

49. Lee, K.T.; Muller, D.A.; Coffey, J.W.; Robinson, K.J.; McCarthy, J.S.; Kendall, M.A.F.; Corrie, S.R. Capture of the Circulating Plasmodium falciparum Biomarker HRP2 in a Multiplexed Format, via a Wearable Skin Patch. Anal. Chem. 2014, 86, 10474-10483. [CrossRef]

50. Yeow, B.; Coffey, J.W.; Muller, D.A.; Grøndahl, L.; Kendall, M.A.F.; Corrie, S.R. Surface Modification and Characterization of Polycarbonate Microdevices for Capture of Circulating Biomarkers, Both in Vitro and in Vivo. Anal. Chem. 2013, 85, 10196-10204. [CrossRef]

51. Muller, D.A.; Corrie, S.R.; Coffey, J.; Young, P.R.; Kendall, M.A. Surface Modified Microprojection Arrays for the Selective Extraction of the Dengue Virus NS1 Protein as a Marker for Disease. Anal. Chem. 2012, 84, 3262-3268. [CrossRef]

52. Corrie, S.R.; Fernando, G.J.P.; Crichton, M.L.; Brunck, M.E.G.; Anderson, C.D.; Kendall, M.A.F. Surface-modified microprojection arrays for intradermal biomarker capture, with low non-specific protein binding. Lab Chip 2010, 10, 2655-2658. [CrossRef]

53. Ng, K.W.; Lau, W.M.; Williams, A.C. Towards pain-free diagnosis of skin diseases through multiplexed microneedles: Biomarker extraction and detection using a highly sensitive blotting method. Drug Deliv. Transl. Res. 2015, 5, 387-396. [CrossRef] [PubMed]

54. Bernier, U.R.; Kline, D.L.; Barnard, D.R.; Schreck, C.E.; Yost, R.A. Analysis of Human Skin Emanations by Gas Chromatography/Mass Spectrometry. 2. Identification of Volatile Compounds That Are Candidate Attractants for the Yellow Fever Mosquito (Aedes aegypti). Anal. Chem. 2000, 72, 747-756. [CrossRef] [PubMed]

55. Soini, H.A.; Bruce, K.E.; Klouckova, I.; Brereton, R.G.; Penn, D.J.; Novotny, M.V. In Situ Surface Sampling of Biological Objects and Preconcentration of Their Volatiles for Chromatographic Analysis. Anal. Chem. 2006, 78, 7161-7168. [CrossRef] [PubMed]

56. Riazanskaia, S.; Blackburn, G.; Harker, M.; Taylor, D.; Thomas, C.L.P. The analytical utility of thermally desorbed polydimethylsilicone membranes for in-vivo sampling of volatile organic compounds in and on human skin. Analyst 2008, 133, 1020-1027. [CrossRef] [PubMed]

57. Zhang, Z.; Pawliszyn, J. Headspace solid-phase microextraction. Anal. Chem. 1993, 65, 1843-1852. [CrossRef] 
58. Camarasu, C.C. Headspace SPME method development for the analysis of volatile polar residual solvents by GC-MS. J. Pharm. Biomed. Anal. 2000, 23, 197-210. [CrossRef]

59. Rocha, S.M.; Ramalheira, V.; Barros, A.A.C.; Delgadillo, I.; Coimbra, M.A. Headspace solid phase microextraction (SPME) analysis of flavor compounds in wines. Effect of the matrix volatile composition in the relative response factors in a wine model. J. Agric. Food Chem. 2001, 49, 5142-5151. [CrossRef]

60. Pini, G.F.; de Brito, E.S.; García, N.H.P.; Valente, A.L.P.; Augusto, F. A Headspace Solid Phase Microextraction (HS-SPME) method for the chromatographic determination of alkylpyrazines in cocoa samples. J. Braz. Chem. Soc. 2004, 15, 267-271. [CrossRef]

61. Zhang, Z.-M.; Cai, J.-J.; Ruan, G.-H.; Li, G.-K. The study of fingerprint characteristics of the emanations from human arm skin using the original sampling system by SPME-GC/MS. J. Chromatogr. B 2005, 822, 244-252. [CrossRef]

62. Sekine, Y.; Toyooka, S.; Watts, S.F. Determination of acetaldehyde and acetone emanating from human skin using a passive flux sampler-HPLC system. J. Chromatogr. B 2007, 859, 201-207. [CrossRef]

63. Duffy, E.; Jacobs, M.R.; Kirby, B.; Morrin, A. Probing skin physiology through the volatile footprint: Discriminating volatile emissions before and after acute barrier disruption. Exp. Dermatol. 2017, 26, 919-925. [CrossRef] [PubMed]

64. Duffy, E.; Albero, G.; Morrin, A. Headspace Solid-Phase Microextraction Gas Chromatography-Mass Spectrometry Analysis of Scent Profiles from Human Skin. Cosmetics 2018, 5, 62. [CrossRef]

65. Gómez-Ríos, G.A.; Reyes-Garcés, N.; Bojko, B.; Pawliszyn, J. Biocompatible Solid-Phase Microextraction Nanoelectrospray Ionization: An Unexploited Tool in Bioanalysis. Anal. Chem. 2016, 88, 1259-1265. [CrossRef] [PubMed]

66. Mirabelli, M.F.; Wolf, J.-C.; Zenobi, R. Direct Coupling of Solid-Phase Microextraction with Mass Spectrometry: Sub-pg/g Sensitivity Achieved Using a Dielectric Barrier Discharge Ionization Source. Anal. Chem. 2016, 88, 7252-7258. [CrossRef]

67. Gómez-Ríos, G.A.; Liu, C.; Tascon, M.; Reyes-Garcés, N.; Arnold, D.W.; Covey, T.R.; Pawliszyn, J. Open Port Probe Sampling Interface for the Direct Coupling of Biocompatible Solid-Phase Microextraction to Atmospheric Pressure Ionization Mass Spectrometry. Anal. Chem. 2017, 89, 3805-3809. [CrossRef]

68. Mosquera, J.; Scholtens, R.; Ogink, N. Using Passive Flux Samplers to determine the ammonia emission from mechanically ventilated animal houses. In Proceedings of the 2003 ASAE Annual Meeting, Las Vegas, NV, USA, 27-30 July 2003; American Society of Agricultural and Biological Engineers: San Jose, MI, USA, 2003.

69. Larios, A.D.; Brar, S.K.; Ramírez, A.A.; Godbout, S.; Sandoval-Salas, F.; Palacios, J.H.; Dubé, P.; Delgado, B.; Giroir-Fendler, A. Parameters determining the use of zeolite 5A as collector medium in passive flux samplers to estimate $\mathrm{N} 2 \mathrm{O}$ emissions from livestock sources. Environ. Sci. Pollut. Res. 2017, 24, 12136-12143. [CrossRef]

70. Larios, A.D.; Kaur Brar, S.; Avalos Ramírez, A.; Godbout, S.; Sandoval-Salas, F.; Palacios, J.H. Challenges in the measurement of emissions of nitrous oxide and methane from livestock sector. Rev. Environ. Sci. Biotechnol. 2016, 15, 285-297. [CrossRef]

71. Debbagh, M.; Adamchuk, V.; Madramootoo, C.; Whalen, J. Development of a Wireless Sensor Network for Passive in situ Measurement of Soil $\mathrm{CO}_{2}$ Gas Emissions in the Agriculture Landscape. In Proceedings of the 14th International Conference on Precision Agriculture, Montreal, QC, Canada, 24-27 June 2018.

72. Fujii, M.; Shinohara, N.; Lim, A.; Otake, T.; Kumagai, K.; Yanagisawa, Y. A study on emission of phthalate esters from plastic materials using a passive flux sampler. Atmos. Environ. 2003, 37, 5495-5504. [CrossRef]

73. Kimura, K.; Sekine, Y.; Furukawa, S.; Takahashi, M.; Oikawa, D. Measurement of 2-nonenal and diacetyl emanating from human skin surface employing passive flux sampler-GCMS system. J. Chromatogr. B 2016, 1028, 181-185. [CrossRef]

74. Furukawa, S.; Sekine, Y.; Kimura, K.; Umezawa, K.; Asai, S.; Miyachi, H. Simultaneous and multi-point measurement of ammonia emanating from human skin surface for the estimation of whole body dermal emission rate. J. Chromatogr. B 2017, 1053, 60-64. [CrossRef]

75. Sekine, Y.; Sato, S.; Kimura, K.; Sato, H.; Nakai, S.; Yanagisawa, Y. Detection of tobacco smoke emanating from human skin surface of smokers employing passive flux sampler-GCMS system. J. Chromatogr. B 2018, 1092, 394-401. [CrossRef] [PubMed]

76. Jiang, C.; Wang, X.; Li, X.; Inlora, J.; Wang, T.; Liu, Q.; Snyder, M. Dynamic Human Environmental Exposome Revealed by Longitudinal Personal Monitoring. Cell 2018, 175, 277-291. [CrossRef] [PubMed] 
77. Roodt, A.P.; Naudé, Y.; Stoltz, A.; Rohwer, E. Human skin volatiles: Passive sampling and GC $\times$ GC-ToFMS analysis as a tool to investigate the skin microbiome and interactions with anthropophilic mosquito disease vectors. J. Chromatogr. B 2018, 1097, 83-93. [CrossRef] [PubMed]

78. O'Connell, S.G.; Kincl, L.D.; Anderson, K.A. Silicone Wristbands as Personal Passive Samplers. Environ. Sci. Technol. 2014, 48, 3327-3335. [CrossRef] [PubMed]

79. Gallardo, E.; Queiroz, J.A. The role of alternative specimens in toxicological analysis. Biomed. Chromatogr. 2008, 22, 795-821. [CrossRef]

80. De Almeida, P.D.V.; Grégio, A.M.T.; Machado, M.A.N.; De Lima, A.A.S.; Azevedo, L.R. Saliva composition and functions: A comprehensive review. J. Contemp. Dent. Pract. 2008, 9, 72-80.

81. Gröschl, M.; Köhler, H.; Topf, H.-G.; Rupprecht, T.; Rauh, M. Evaluation of saliva collection devices for the analysis of steroids, peptides and therapeutic drugs. J. Pharm. Biomed. Anal. 2008, 47, 478-486. [CrossRef]

82. Higashi, T. Salivary Hormone Measurement Using LC/MS/MS: Specific and Patient-Friendly Tool for Assessment of Endocrine Function. Biol. Pharm. Bull. 2012, 35, 1401-1408. [CrossRef]

83. Bessonneau, V.; Boyaci, E.; Maciazek-Jurczyk, M.; Pawliszyn, J. In vivo solid phase microextraction sampling of human saliva for non-invasive and on-site monitoring. Anal. Chim. Acta 2015, 856, 35-45. [CrossRef]

84. Chen, L.C.; Naito, T.; Tsutsui, S.; Yamada, Y.; Ninomiya, S.; Yoshimura, K.; Takeda, S.; Hiraoka, K. In vivo endoscopic mass spectrometry using a moving string sampling probe. Analyst 2017, 142, 2735-2740. [CrossRef]

85. Semba, R.D.; Enghild, J.J.; Venkatraman, V.; Dyrlund, T.F.; Van Eyk, J.E. The Human Eye Proteome Project: Perspectives on an emerging proteome. Proteomics 2013, 13, 2500-2511. [CrossRef] [PubMed]

86. Sharma, S. Diagnosis of infectious diseases of the eye. Eye 2012, 26, 177-184. [CrossRef] [PubMed]

87. Stamer, W.D.; Williams, A.M.; Pflugfelder, S.; Coupland, S.E. Accessibility to and Quality of Human Eye Tissue for Research: A Cross-Sectional Survey of ARVO Members. Invest. Ophthalmol. Vis. Sci. 2018, 59, 4783-4792. [CrossRef] [PubMed]

88. Liou, Y.-W.; Chang, K.-Y.; Lin, C.-H. Sampling and profiling caffeine and its metabolites from an eyelid using a watercolor pen based on electrospray ionization/mass spectrometry. Int. J. Mass Spectrom. 2017, 422, 51-55. [CrossRef]

89. Lopez, C.; Park, S.; Edwards, S.; Vong, S.; Hou, S.; Lee, M.; Sauerland, H.; Lee, J.-J.; Jeong, K.J. Matrix Metalloproteinase-Deactivating Contact Lens for Corneal Melting. ACS Biomater. Sci. Eng. 2019, 5, 1195-1199. [CrossRef]

90. Maruyama, S.; Kikuchi, K.; Hirano, T.; Urano, Y.; Nagano, T. A Novel, Cell-Permeable, Fluorescent Probe for Ratiometric Imaging of Zinc Ion. J. Am. Chem. Soc. 2002, 124, 10650-10651. [CrossRef]

91. Hemalatha, R.G.; Ganayee, M.A.; Pradeep, T. Electrospun Nanofiber Mats as "Smart Surfaces" for Desorption Electrospray Ionization Mass Spectrometry (DESI MS)-Based Analysis and Imprint Imaging. Anal. Chem. 2016, 88, 5710-5717. [CrossRef]

92. Li, W.; Chen, X.; Wang, Z.; Wong, Y.E.; Wu, R.; Hung, Y.-L.W.; Chan, T.-W.D. Tissue imaging with in situ solid-phase extraction micro-funnel based spray ionization mass spectrometry. Eur. J. Mass Spectrom. 2018, 24, 66-73. [CrossRef]

(C) 2019 by the authors. Licensee MDPI, Basel, Switzerland. This article is an open access article distributed under the terms and conditions of the Creative Commons Attribution (CC BY) license (http://creativecommons.org/licenses/by/4.0/). 